\title{
NPC Three-Level Inverter Open-Circuit Fault Diagnosis Based on Adaptive Electrical Period Partition and Random Forest
}

\author{
Shiyuan Liu, ${ }^{1}$ Xu Qian $\mathbb{D}^{1}{ }^{1}$ Hong Wan, ${ }^{2}$ Zongbin Ye, ${ }^{3}$ Shoupeng $W u,{ }^{2}$ and Xiaohong Ren ${ }^{3}$ \\ ${ }^{1}$ School of Mechanical Electronic \& Information Engineering, China University of Mining and Technology, Beijing 100083, China \\ ${ }^{2}$ IOT Perception Mine Research Center, China University of Mining and Technology, Xuzhou 221000, China \\ ${ }^{3}$ School of Electrical and Power Engineering, China University of Mining and Technology, Xuzhou 221000, China
}

Correspondence should be addressed to Xu Qian; qxcumtbj@163.com

Received 1 August 2019; Accepted 20 December 2019; Published 17 January 2020

Academic Editor: Qiang Wu

Copyright (C) 2020 Shiyuan Liu et al. This is an open access article distributed under the Creative Commons Attribution License, which permits unrestricted use, distribution, and reproduction in any medium, provided the original work is properly cited.

Fault detection can increase the reliability and efficiency of power electronic converters employed in power systems. Among the converters in the power system, a Neutral Point Clamped (NPC) three-level inverter is most commonly used to drive electric motors. In this paper, a new approach for open-circuit fault detection and location of the NPC three-level inverter for a shifting process using a constant voltage-to-frequency ratio is proposed. In order to diagnose open-circuit fault in as short a time as possible, an adaptive electrical period partition (AEPP) algorithm is proposed to pick single electrical periods from real-time three-phase current signals. The Maximal Overlap Discrete Wavelet Transformation (MODWT) and Park's Vector Modulus (PVM) are used for feature analysis and normalization of electrical period signals. The statistical characteristics of the electrical period signals are extracted, and a random forest model is constructed to realize the state classification. Compared with the traditional fault diagnosis method, the proposed algorithm finds fault locations quickly and accurately. The effectiveness and accuracy of the proposed algorithm are verified by experiments.

\section{Introduction}

As the key device that converts DC signals into AC signals, inverters are widely used in electrical power control devices, such as mine hoists and belt control systems. Neutral Point Clamped (NPC) three-level inverters are most commonly used because of their advantages of lower harmonic distortion in the voltage output and less impact on the load. Insulated Gate Bipolar Transistors (IGBTs) are used as power switches in inverters, operating under high voltage, high temperature, and high frequency in an on-and-off situation for a long time. Due to excess electrical and thermal stress, IGBT failures have the highest probability of all faults of the inverter [1]. Compared with a two-level inverter, a three-level inverter has more power switches, leading to more complex circuits and increased instability [2]. Most common power switch faults in the inverter are shortcircuit or open-circuit faults. In most cases, short-circuit faults cause over-current conditions, which can be detected by standard protection systems, such as fuse, relay, and circuit breakers. Standard protection systems disconnect the power supply in order to protect associated components from damage. In contrast, open-circuit faults generally do not cause shutdown of the system; instead, they degrade performance, even leading to severe secondary faults in other parts of the system. Since open-circuit faults cannot be detected by the standard protection system, open-circuit faults are the focus of this paper.

Since fault diagnosis of open-circuit faults is critical for the inverter $[3,4]$, researchers have become more and more interested in fault diagnosis of complicated systems in the last few decades. A large number of fault diagnosis methods have been proposed by researchers for open-circuit faults. These methods can be classified into voltage-based and currentbased methods. Generally, voltage-based methods realize the diagnosis by comparing the differences between faulty voltage and normal reference voltage. In [5], a fault diagnosis method based on the zero voltage vector sampling method 
for sampling current and reconstructing three-phase current was proposed. In [6], a multiscale adaptive fault diagnosis method based on signal symmetric reconstruction preprocessing was recommended to diagnose arbitrary switching faults of microgrid inverters under variable load conditions. [7] developed a strategy for identifying open-circuit faults by constructing standardized variables for fault modes. In [8], a fault model based on the envelope of the voltage between the output lines of the inverter was used for fault diagnosis. [9] proposed an analytical model based on the difference between the instantaneous voltage of the fault state and the measured signal. However, voltage-based methods need additional voltage sensors and complex analysis unit and are easily affected by the change of load.

Current-based open-circuit fault diagnosis methods based on the output current change trend and direction of the power switches [10] are mostly used in inverters. Park's transform methods are commonly adopted in current-based methods. In [11], a fault diagnosis method based on the average of the current and instantaneous angles of the current vector was advanced. In [12], an open-circuit fault diagnosis method based on the normalized mean current Park's Vector Modulus (PVM) and angle was proposed. In [13], the average current parking vector was used to construct a three-level NPC signature table for possible fault conditions. A converter-based hybrid logic dynamic (MLD) model was used to estimate the opencircuit fault of grid current in [14]. In [15], an opencircuit fault diagnosis strategy based on the change of rotor current was offered. [16] proposed that fault diagnosis of the T-type multilevel converter is achieved by monitoring the abnormal change of the neutral current of the DC bus. [17] put forth a three-phase voltage source inverter (VSI) current sensor and open circuit fault diagnosis algorithm based on adaptive threshold. Park transform methods are required to compare with the set threshold to realize the diagnosis. Setting the threshold value to a constant when the load changes is difficult because the current amplitude cannot be predicted. Therefore, it is difficult to guarantee the accuracy of these fault diagnosis methods and apply them in actual systems.

Uncertainty is a great challenge in the fault diagnosis of inverters. The uncertainty can be caused by several factors, such as bias and noise of sensors. Motivated by solving these uncertainty problems, we propose a data-driven fault diagnosis methodology in three-phase inverters. Recently, many algorithms based on signal and knowledge methods have shown good performance in the fault diagnosis of inverters [18]. In [19], a three-phase inverter fault diagnosis method based on Bayesian network was proposed. In [20], spectral kurtosis (SK) based on Choi-Williams distribution (CWD) and wavelet-packet energy Shannon entropy (WPESE) are used for the fault detection, and the DC component method is used for the fault localization for open switch faults in the closed-loop inverter. In [21], a principle of low-frequency sampling of the main fault components and neural networks for classification was established for the fault diagnosis of inverters. In [22], a neural network fault diagnosis method based on current Park's Vector Transform (PVT) and dis- crete wavelet transform (DWT) was recommended. In [23], an online fault diagnosis model was offered with wavelet decomposition for processing fault current signals and SVM for classification. The diagnosis methods in [18-23] focused on the open-circuit fault of a two-level inverter. However, the three-level inverter consists of more power switches than a two-level inverter, resulting in a more complex circuit structure and lower reliability. Therefore, the possibility of faults in a three-level inverter is higher, and the types of faults are more diverse [2]. In [24], the feature was extracted by Fast Fourier Transform (FFT) and classified by support vector machine (SVM) to detect faults of the multilevel inverter. But in this paper, fault characteristics are extracted from the output voltage waveform and only pure $R$ load is analyzed while the loads in the power system generally are RL type. Also, the FFT method is used for signal analysis. This analysis does not have good performance in transient states of the system and cannot show us the time of the fault occurrence.

The fault diagnosis algorithms implemented in the previous research papers are mainly based on signals under constant speed condition or conditions in different speeds of the motor, rarely considering the shifting process. A constant voltage-to-frequency ratio method is used to adjust the speed during the shifting process while the amplitude and frequency change throughout the whole process. Compared to constant speed, the signal analysis of the shifting process is more complex. Moreover, traditional threshold and feature analysis methods tend to perform poorly because of the changing amplitude and frequency when used in practical applications. The proposed fault diagnosis method in this paper, on the other hand, is used particularly to diagnose open-circuit fault during the shifting process of the NPC inverter.

The proposed method consists of three parts: signal analysis, fault feature extraction, and fault identification. In the first part, signal analysis, a period partition algorithm is designed to pick electrical periods from the output three-phase current signals. The electrical period is decomposed by three-level MODWT, and PVM is used to normalize the low-frequency approximation component which is retained for fault diagnosis during the shifting process. Then, in fault feature extraction, 11 signal statistical characteristics are extracted as fault features. Last, in fault identification, RF is used to identify faults according to fault features. The simulation based on MATLAB/Simulink and a test-bed using a converter of coal mine hoist is constructed to verify the proposed method, in which a motor acceleration process of the hoist is set up to simulate the shifting process of the NPC inverter. The result shows that this method has good robustness and can solve the problem of noise misdiagnosis.

The organization of the paper is as follows. In Section 2, the main faults of the three-level NPC inverter are analyzed. In Section 3, an electrical period partition method is proposed. In Section 4, the new fault diagnosis algorithm is constructed. In Section 5, the effectiveness of the proposed fault diagnosis algorithm is demonstrated by simulation and experimental results. 


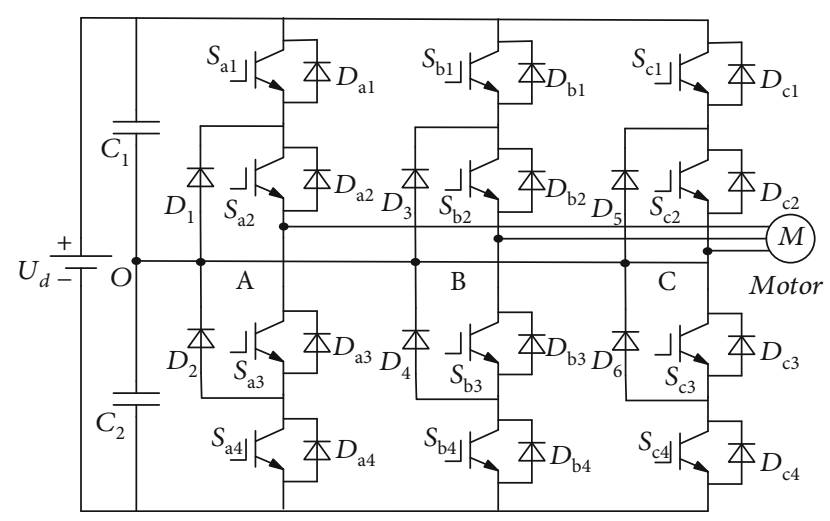

Figure 1: Topology of the NPC three-level inverter.

\section{NPC Three-Level Inverter Fault Analysis}

The structure of the NPC inverter is detailed in Figure 1. The inverter is composed of the DC bus and three legs (A, B, and C). Each leg includes four IGBTs, four free-wheeling diodes, and two clamping diodes. Each free-wheeling diode has an antiparallel connection with the power switch to provide a reverse conduction loop for the current. The $\mathrm{C}$ bus has two capacitors providing the middle point "O." Capacitors $C_{1}$ and $C_{2}$ can absorb the power difference between the rectifier and the inverter, and support the dc link. $U_{d}$ denotes the dclink voltage. Motor $M$ is the load. The NPC inverter is used for generating the three voltages applied across the windings of the motor. The state of each power switch is controlled by the corresponding gate signal. When the gate signal is 1 (high level), the power switch is turned on; when the gate signal is 0 (low level), the power switch is turned off.

During healthy operation of the NPC three-level inverter, the three-phase current signals at the output of the inverter are sinusoidal and have a phase difference of $120^{\circ}$. Signals of phase-A output current at normal and four different fault conditions are shown in Figures 2 and 3, which were acquired under an acceleration process using the constant voltagefrequency-ratio control method. In this paper, the threephase output current signals are used as the raw data for the diagnosis of the open-circuit fault.

\section{Electrical Period Partition Algorithm}

In order to take timely protective measures in practical application systems, one hopes to diagnose open-circuit fault as quickly as possible. From the analysis of the three-phase output current signal in different fault states, fault features can be extracted from one electrical period of the three-phase current signals. However, in the scenarios analyzed in this paper, the period of the output current signal is constantly changing, as shown in Figure 2. Therefore, we need to partition the electrical period from the changing period's current signal. Because the period and amplitude of the current signals of inverter output are consistent with the control target, we can partition the current electrical period output by synchronizing it with the control signal. However, this method requires strict time synchronization, so a real-time commu-

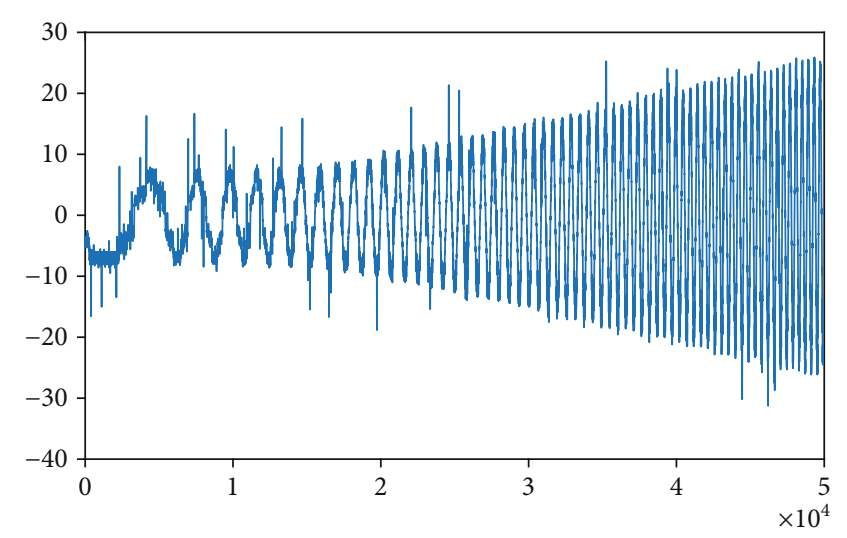

Figure 2: Signal of phase-A current at normal state.

nication mechanism is needed between the output current signal acquisition terminal and the control terminal, which increases the cost of software and hardware. Thus, an adaptive electrical period partition (AEPP) algorithm, which mainly depends on the characteristics of the output current signal, is proposed. In the AEPP algorithm, target signal information from the control terminal is needed, but strict time synchronization is not necessary; instead, asynchronism within $50 \mathrm{~ms}$ is allowed.

Because of the nonstationary characteristics of the output current signals, as shown in Figures 2 and 3, the following problems need to be resolved for the AEPP algorithm:

(1) There are various noise interference problems in the signal

(2) The period value and peak value in one period of the output current signal are constantly changing during the acceleration process

(3) It is difficult to locate the peak and valley of one signal period, especially in the low-frequency stage of the output current. The maximum and minimum positions cannot represent the peak and valley, as shown in Figure 4

(4) Half-cycle malformations or missing output currents caused by open-circuit fault must be addressed

In the AEPP algorithm, the acquisition terminal regularly obtains target period value Tref and peak value Aref from the control terminal, which can help to solve problems (1) and (2). The Tref and Aref here are just reference values, so strict time synchronization between the acquisition terminal and control terminal is not necessary.

In Figure 5, the AEPP algorithm is depicted. The steps can be described as follows:

Step 1. Get Tref and Aref from the control terminal.

Step 2. Use the sliding window to obtain a continuous $100 \mathrm{~ms}$ current signal, of which $98 \mathrm{~ms}$ is the historical signal and $2 \mathrm{~ms}$ is the real-time signal to be analyzed. 


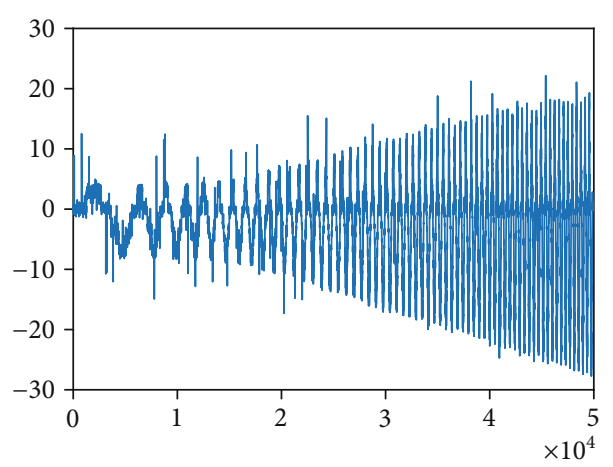

(a) $S_{\text {a1 }}$ open fault

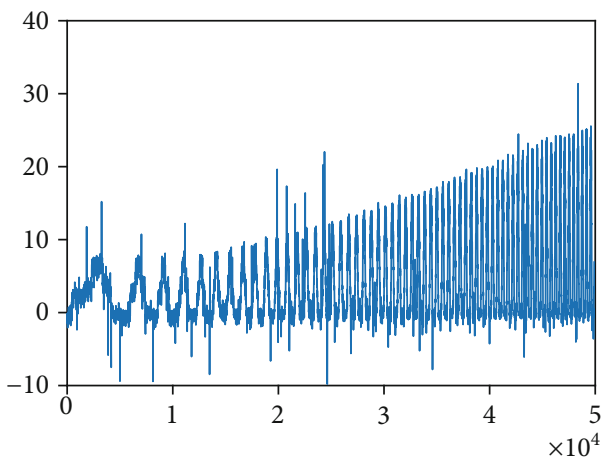

(c) $S_{\mathrm{a} 3}$ open fault

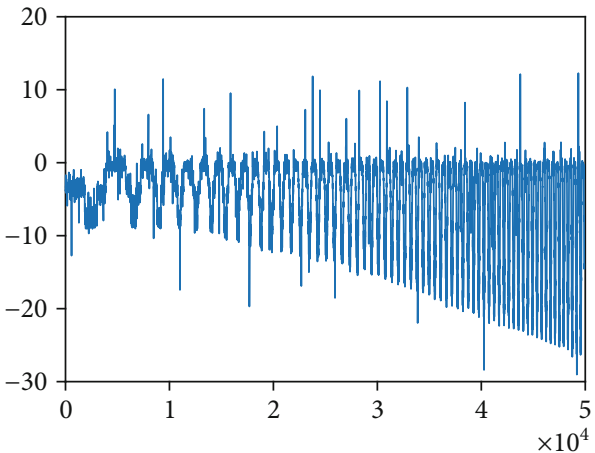

(b) $S_{\mathrm{a} 2}$ open fault

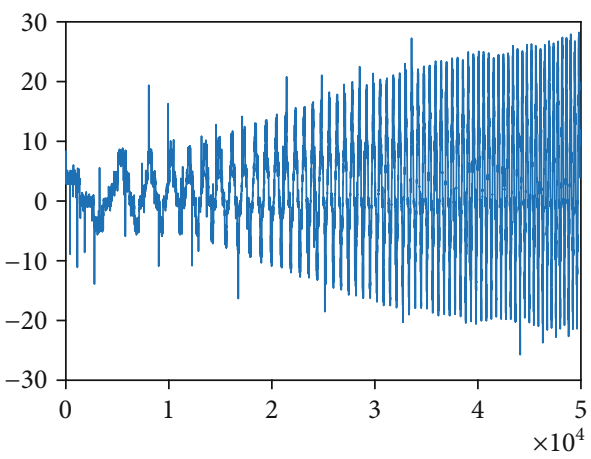

(d) $S_{\text {a4 }}$ open fault

FIgURE 3: Signals of phase-A current at different fault conditions.

Step 3. Suppress noise interference for the $100 \mathrm{~ms}$ sliding window signal by LMS filter.

Step 4. Search the peak and valley of the current cycle in the former $1 \mathrm{~ms}$ real-time signal with Tref and Aref. The specific details of the search process are shown in Figure 6.

Step 5. Determine which of the following next steps is appropriate based on Step 4's search results:

(a) There is no peak and valley in the $1 \mathrm{~ms}$ signal. Then go straight to Step 6

(b) The peak is found. Because of the existence of halfcycle malformations or missing output as described in problem (4), the peak value and location are used for the valley adjustment (as show in Figure 3(c), the valley cannot be located with the strict restrictions)

(c) The valley is found. Adjust the peak location, similar to Step $5 b$

Step 6. Make the sliding window slide forward $1 \mathrm{~ms}$, and update Tref and Aref according to the communication information with the control terminal.

Here, a three-point location method is proposed for the peak search process in Step 4. As shown in Figure 7, when the three peak maker points F1, F2, and F3 are found in order from F1 to F3, the peak is located. F1 is the start marker of the peak, the value of which is $0.2 *$ Aref; F2 is the entry maker of the peak, the value of which is $0.7 *$ Aref; F3 is the end of the peak, the value of which is $0.2 *$ Aref.

The specific peak search process using the three-point location method is shown in Figure 6. The process can be described as follows:

Step 1. Obtain a sampling point from the $1 \mathrm{~ms}$ real-time signal.

Step 2. Execute judgment logic based on the current locating maker point. If the sampling point value does not satisfy the threshold of the current located maker point, go back to Step 1; otherwise, go to Step 3.

Step 3. Get $1 \mathrm{~ms}$ successive signal points before the sampling point, and Step 1 and $1 \mathrm{~ms}$ points after the sampling point. The successive $2 \mathrm{~ms}$ signal points are used to verify the located marker point. If the validation condition passes, go back to Step 1; otherwise, go to Step 4 .

\section{Step 4.}

(a) If F1 is located, change the current locating maker point to F2 


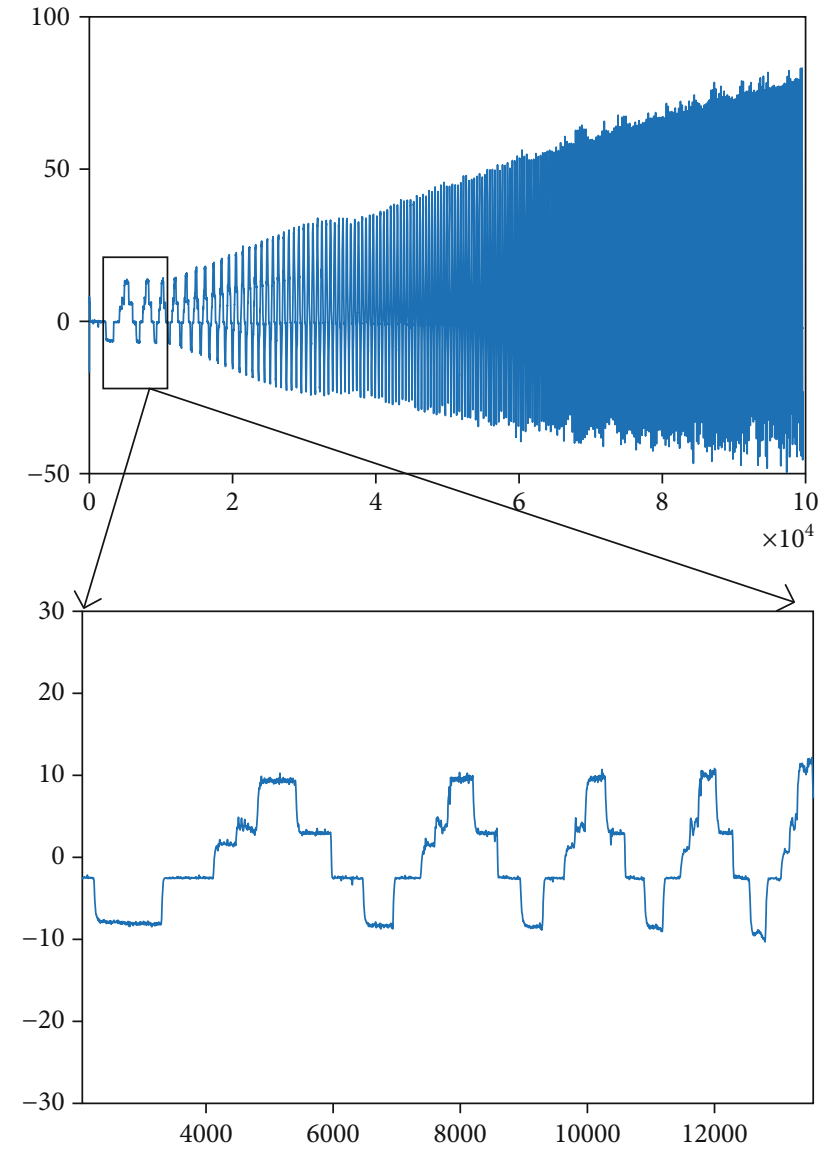

Figure 4: The low-frequency stage of the output current.

(b) If F2 is located, rectify the F1 location to remove the interference such as F1, as shown in Figure 7, and change the current locating maker point to F3

(c) If F3 is located, find the maximum value between F2 and $\mathrm{F} 3$ as the peak point, and calculate $\mathrm{T} 1$ and $\mathrm{T} 2$. If T1 and T2 match the threshold based on Tref, the real peak is located; otherwise, the located peak is noise, so change the current locating maker point to F2, and go back to Step 1

Step 5. Search point F4 between F2 and F3 and midpoint of $\mathrm{F} 2$ and F4 is located as the peak point.

The main computation work in AEPP is the peak and valley location. When the sampling frequency is $10 \mathrm{kHz}$, there are only 10 sampling points which need to compared with Aref in an $1 \mathrm{~ms}$ signal for the peak and valley search process. Therefore, AEPP has a low calculation complexity.

\section{Fault Diagnosis Model}

4.1. Park's Vector Modulus (PVM). During healthy operation, the perfectly balanced three-phase current signals at the output of the inverter are given as

$$
\left\{\begin{array}{l}
i_{a}=I_{m} \sin w t \\
i_{b}=I_{m} \sin \left(\frac{w t+2}{3 \pi}\right), \\
i_{c}=I_{m} \sin \left(\frac{w t-2}{3 \pi}\right),
\end{array}\right.
$$

where $i_{a}, i_{b}, i_{c}$ are the instantaneous values of the three-phase current, $I_{m}$ is the maximum amplitude of current, and $w$ is the current frequency. To make the system load independent, the three-phase current is normalized as

$$
i_{k m}=\frac{i_{k}}{I_{m}},
$$

where $k=a, b$, or $c$ and $i_{k m}$ is the normalized current within the range of 1 , which is useful for the normalization of three-phase currents under variable load conditions. But it cannot suppress high transients caused by load variations. These transients can be suppressed with a PVM without altering the nature of transients generated as a result of fault occurrence [25]. The DQ transformation, or PVT, which is used to transform three-phase currents $\left(i_{a}, i_{b}, i_{c}\right)$ into twophase currents $\left(i_{d}, i_{q}\right)[26]$, is given as

$$
\left(\begin{array}{l}
i_{d} \\
i_{q}
\end{array}\right)=\sqrt{\frac{2}{3}}\left(\begin{array}{ccc}
1 & -\frac{1}{2} & -\frac{1}{2} \\
0 & \frac{\sqrt{3}}{2} & -\frac{\sqrt{3}}{2}
\end{array}\right)\left(\begin{array}{c}
i_{a} \\
i_{b} \\
i_{c}
\end{array}\right) .
$$

PVM is calculated as

$$
\left|\overline{i_{\text {park }}}\right|=\sqrt{i_{d}^{2}+i_{q}^{2}}
$$

Divided by PVM, the normalized three-phase current is given as [27]

$$
i_{\text {kpark }}=\frac{i_{k}}{\left|\overline{i_{\text {park }}}\right|},
$$

where $k=a, b$, or $c$ and $i_{k \text { park }}$ is the normalized three-phase current.

4.2. Maximal Overlap Discrete Wavelet Transform (MODWT). DWT is a very useful and efficient method for the analysis of the current signal in a static and dynamic state system. Also, unlike other methods based on the frequency method the same as FFT, DWT has good performance under transient conditions. The MODWT is an improvement based on DWT that addresses the following limitations [28]:

(1) It requires the sample size to be exactly a power of 2 for the full transform because of the down sampling step in the DWT

(2) The results of the DWT analysis change due to the cyclic displacement. When the signal is subjected to the corresponding cyclic shift, the wavelet coefficients 


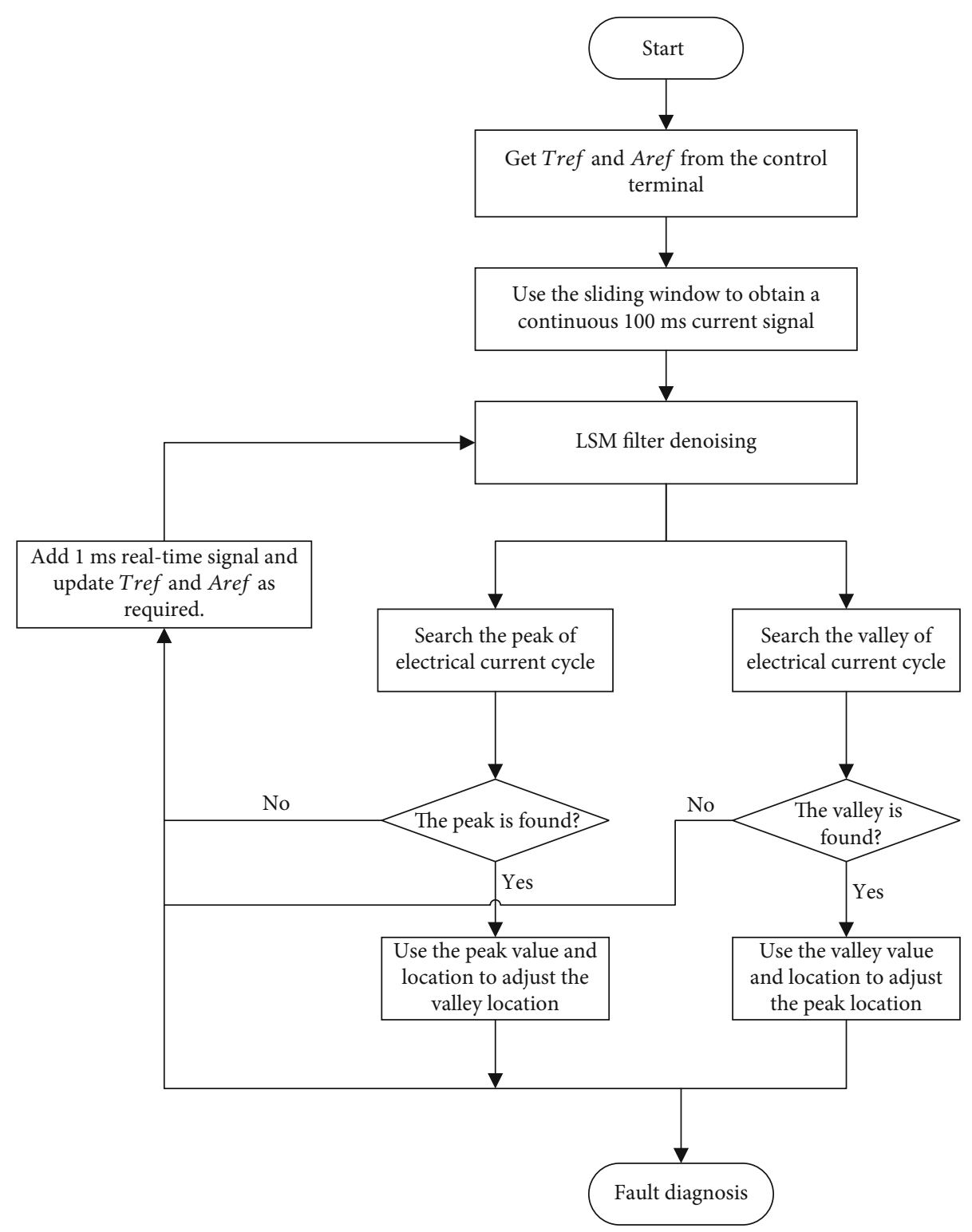

FIgURE 5: The AEPP algorithm workflow.

and scale coefficients of the signal DWT cannot achieve the same cyclic displacement

(3) As the DWT decomposition series increases, its scale factor and wavelet coefficient are halved, affecting the statistical analysis of the coefficients

In view of the above limitations, MODWT is proposed. While the DWT of level $j$ restricts the sample size to an integer multiple of $2^{j}$, the MODWT of level $j$ is well defined for any sample size $N$. A scaling of the defining filters is required to conserve energy, and filters are given by

$$
\begin{aligned}
& \tilde{g}_{l}=\frac{g_{l}}{\sqrt{2}}, \\
& \tilde{h}_{l}=\frac{h_{l}}{\sqrt{2}} .
\end{aligned}
$$

By inserting $2^{j-1}-1$ zeros into the filters $\left\{\tilde{g}_{l}\right\}$ and $\left\{\tilde{h}_{l}\right\}$ at scale $j$, MODET improves the problem that the wavelet coefficients and scale coefficients are halved accordingly as the number of DWT stages increases. The scale transform coefficients (approximation) and wavelet transform coefficients (details) of MODWT at its scale $j$ are

$$
\begin{aligned}
V_{j, t}^{\prime} & =\sum_{l=0}^{l-1} \tilde{g}_{l} V_{j-1,(2 t+1-l) \bmod N_{j}-1} \quad\left(t=0, \cdots, N_{j}-1\right), \\
W_{j, t}^{\prime} & =\sum_{l=0}^{l-1} h_{l} V_{j-1,(2 t+1-l) \bmod N_{j}-1} \quad\left(t=0, \cdots, N_{j}-1\right) .
\end{aligned}
$$

4.3. Random Forest $(R F)$. In order to improve the efficiency and accuracy of diagnosis results, RF combined with 


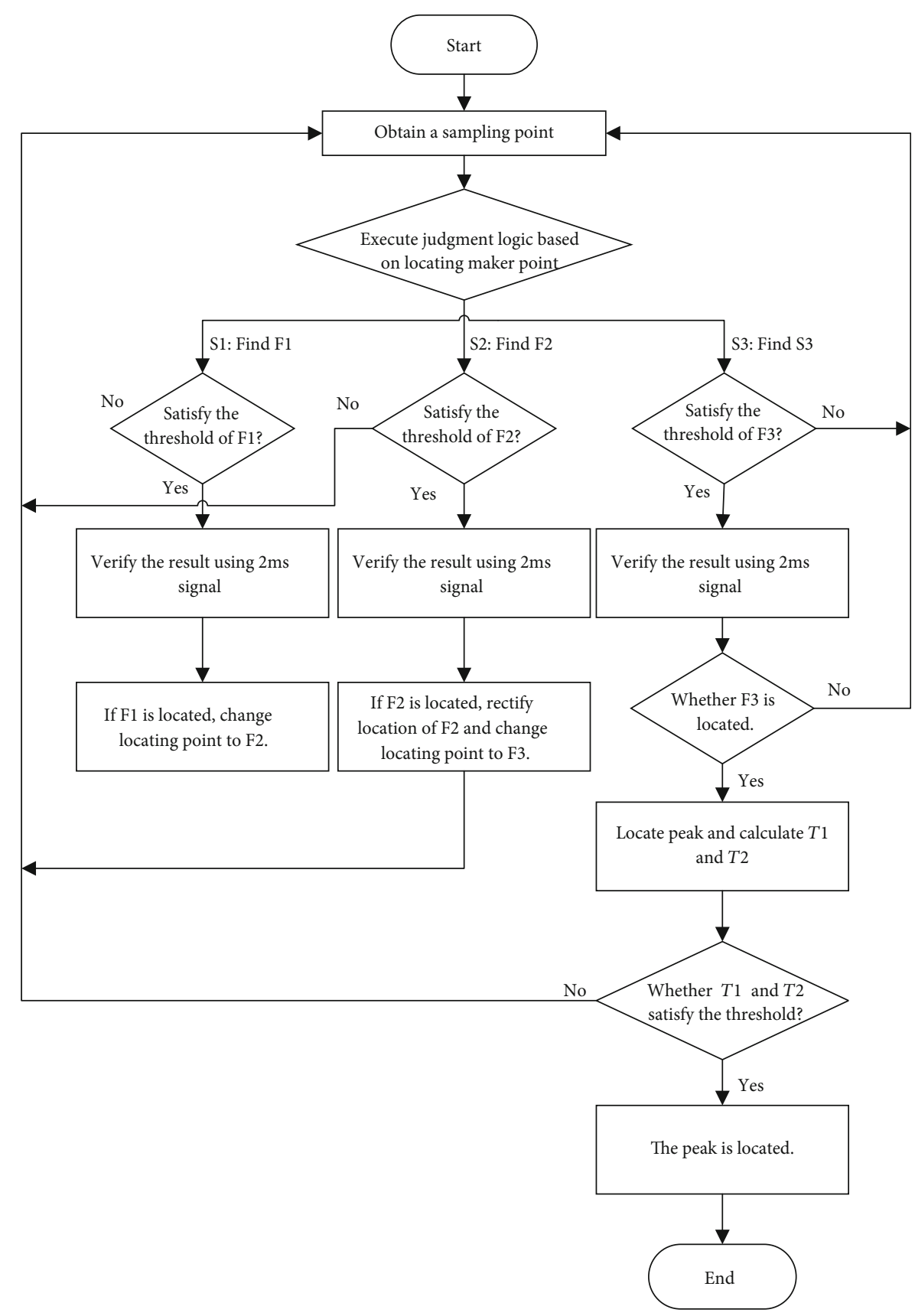

FIGURE 6: The peak search process of AEPP algorithm.

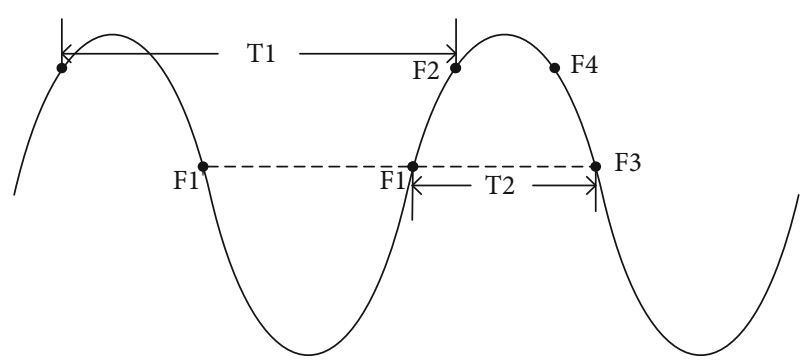

FIGURE 7: Three-point location method for the peak search process. extracted features is investigated for the fault diagnosis of the NPC three-level inverter [29]. RF is an ensemble classifier based on decision tree that trains multiple models by using the statistical sampling principle. It can improve the accuracy and stability of the model by reducing the sensitivity to data noise. A subset of features is randomly selected in RF. The $\mathrm{RF}$ construction steps are as follows:

Step 1. Randomly extract $n$ samples from the original dataset, and randomly select $k$ features and the best feature for node segmentation. 


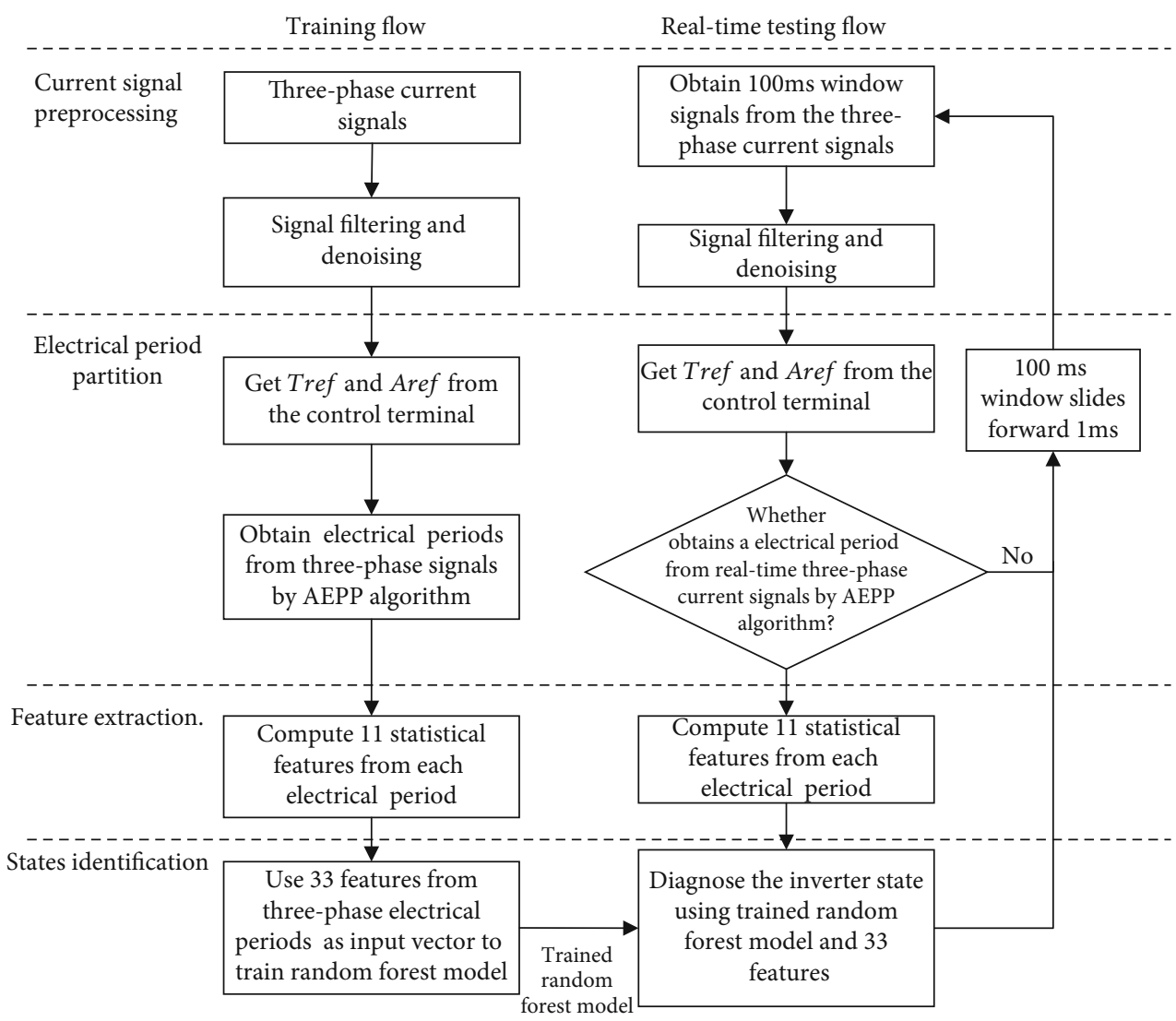

FIGURE 8: Workflow of proposed open-circuit fault diagnosis model.

Step 2. For the new sample set (with $n$ samples and $k$ features), Gini of the probability distribution of the node $n$ is

$$
I_{\text {Gini }}(n)=\sum_{k=1}^{K} p_{k}\left(1-p_{k}\right)=1-\sum_{k=1}^{K} p_{k}^{2}
$$

The CART tree, which is a binary tree $K=2$, can be expressed as follows:

$$
I_{\text {Gini }}(n)=2 p(1-p)
$$

For each feature $A$ and its possible value $a$, calculate $\operatorname{Gini}(D, A)$ according to Step 2:

$$
\operatorname{Gini}(D, A)=\frac{\left|D_{1}\right|}{|D|} \operatorname{Gini}\left(D_{1}\right)+\frac{\left|D_{2}\right|}{|D|} \operatorname{Gini}\left(D_{2}\right)
$$

Step 3. Select the optimal feature and segmentation point. For each node on the RF, features are randomly extracted from the $d$-dimensional feature set. A feature is selected according to the Gini maximization principle [29], which divides the data on the node into left and right child nodes. That is, assuming that the data on the parent node $n_{p}$ is divided into its child nodes $n_{l}$ and $n_{r}$, the Gini maximization principle is to maximize

$$
\Delta I_{\text {Gini }}=I_{\text {Gini }}\left(n_{p}\right)-p_{l} * I_{\text {Gini }}\left(n_{l}\right)-p_{r} * I_{\text {Gini }}\left(n_{r}\right) .
$$

Step 4. Recursively return to Step 2 and Step 3 for these two child nodes to build a decision tree with $n$ samples and $k$ features.

Step 5. Repeat Step 1 to Step 4 to build decision trees and form the RF.

For classification problems, the final category of the prediction is the category with the highest number of votes in the sample leaf node.

4.4. Proposed Open-Circuit Fault Diagnosis Model. The implementation of the proposed open-circuit fault diagnosis model is shown in Figure 8, where the signal analysis, feature extraction, and artificial intelligence approaches are systematically blended to detect open-circuit faults of the inverter. The whole procedure is divided into the following four steps:

Step 1. Current Signal Preprocessing. Because of the interference of the electrical environment, current signals collected by hardware system are mixed with noise. The LMS filter is used for denoising. 
Step 2. Electrical Period Partition. With the Tref and Aref obtained from the control terminal, the electrical periods of three-phase signals are partitioned by the AEPP algorithm for the training dataset, while the $100 \mathrm{~ms}$ window signals slide forward with the three-phase current real-time acquisition and is processed by the AEPP algorithm for real-time testing signals.

Step 3. Feature Extraction. The electrical period is decomposed by three-level MODWT, and only the low-frequency approximation component is retained for normalization using PVM. Then, 11 features in Table 1 are computed for the normalized signal, which is reconstructed by the lowfrequency component of electrical period.

Step 4. State Identification. $33(11 * 3)$ features from electrical periods of the three-phase current are used as the input vector to train the RF model with state label in the training flow, while the trained RF model is used for state identification with feature vector as the input for the real-time testing signal.

\section{Experimental and Analytical Results}

5.1. Experiment Setup. The simulation in the MATLAB/Simulink environment and the experiment were carried out to verify the feasibility of the proposed fault diagnosis method of the NPC three-level inverter. A DC/AC transform was accomplished by Space Vector Pulse Width Modulation (SVPWM), and the input DC voltage was $540 \mathrm{~V}$. Figure 9 shows the simulation circuit model for inverter faults.

A $4 \mathrm{~s}$ acceleration process using a constant voltagefrequency-ratio was simulated, in which different combinations of resistors and inductors were used to simulate the change of load as Table 1 lists. The 13 kinds of inverter states (healthy state and 12 kinds of single IGBT open faults of $S_{\mathrm{al}}$, $S_{\mathrm{a} 2}, \ldots, S_{\mathrm{c} 4}$ ) were studied in this paper. The current sampling frequency was $10 \mathrm{kHz}$. $4 \mathrm{~s}$ three-phase current signals at 13 states were collected to set up dataset Case 1, for which 35 sets of loads, as shown in Table 2, were simulated. There were 455 ( $35 * 13,35$ types of loads, 13 kinds of states) groups of three-phase current signals in Case 1.

Meanwhile, we set up a three-level NPC inverter fault current signal acquisition test-bed using the converter of coal mine hoist shown as Figure 10, consisting of a converter with a three-level NPC inverter, DC power supply, load with resistance and inductance, oscilloscope, and so forth. The 13 kinds of inverter states under different loads were analyzed using the test-bed. The DC power supply was $550 \mathrm{~V}$, and the output current signals could be obtained via the hardware circuit experiments with different loads. The experiments were conducted by four different loads: (1) $R=0.5 \Omega, L=$ $1.5 \mathrm{mH}$; (2) $R=0.5 \Omega, L=2 \mathrm{mH}$; (3) $R=1 \Omega, L=1.5 \mathrm{mH}$; and (4) $R=1 \Omega, L=2 \mathrm{mH}$. The sampling frequency of the current signal was $10 \mathrm{kHz}$. Three-phase current signals were collected for a $10 \mathrm{~s}$ acceleration process using the constant voltage-to-frequency ratio during each experiment. Five sets of three-phase current signals were collected for $52(4 * 13,4$ types of loads, 13 kinds of states) working conditions. A total
TABLE 1: Statistical features.

\begin{tabular}{lc}
\hline Feature & Expression $(x(i)$ is the analysis signal $)$ \\
\hline $\begin{array}{l}\text { Max value } \\
\text { Min value }\end{array}$ & $T_{1}=\max (x(i))$ \\
Range & $T_{3}=\max (|x(i)|)-\min (|x(i)|)$ \\
Mean value & $T_{4}=\left(\frac{1}{n}\right) \sum_{i=1}^{n} x(i)$ \\
Standard deviation & $\sqrt{\left(\frac{1}{(n-1)}\right) \sum_{i=1}^{n}\left(x(i)-T_{1}\right)^{2}}$ \\
Kurtosis & $T_{6}=\frac{\sum_{i=1}^{n}\left(x(i)-T_{1}\right)^{3}}{\left((n-1) T_{2}^{3}\right)}$ \\
Skewness & $T_{7}=\frac{\sum_{i=1}^{n}\left(x(i)-T_{1}\right)^{3}}{\left((n-1) T_{2}^{3}\right)}$ \\
Crest factor & $T_{8}=\frac{\max |x(i)|}{\sqrt{(1 / n) \sum_{i=1}^{n} x(i)^{2}}}$ \\
Impulse factor & $T_{9}=\frac{\max (|x(i)|)}{\sqrt{(1 / n) \sum_{i=1}^{n}|x(i)|}}$ \\
Shape factor & $T_{10}=\frac{\sqrt{(1 / n) \sum_{i=1}^{n} x(i)^{2}}}{(1 / n) \sum_{i=1}^{n}|x(i)|}$ \\
\end{tabular}

of $260(5 * 52)$ groups of three-phase current signals were used as Case 2.

The control method of the NPC three-level inverter used in this paper is SVPWM. The output current signal presents a sinusoidal characteristic as a whole, but the amplitude will also fluctuate slightly. When the sampling frequency is reduced to $1 \mathrm{kHz}$, the detailed characteristics of the current signal are almost completely lost. Therefore, the sampling frequency of the current signal in the experimental analysis phase is $10 \mathrm{kHz}$. In the engineering application, in order to reduce costs, a lower current sampling frequency will be considered.

5.2. Signal Denoising Analysis. The raw phase-A current signals under normal state and $S_{\mathrm{a} 1}$ open-fault state of Case 2 are shown in Figures 11(a) and 12(a). It is clear that heavy noise interfered with the signal. The denoised signals using the LMS filter are shown in Figures 11(b) and 12(b). Figures 11(c) and 12(c) show that the noise in the denoised signals could be effectively suppressed by the LMS filter; furthermore, the structural characteristics and waveform feature were well-preserved, which could increase fault diagnosis precision.

5.3. Electrical Period Partition Result. The AEPP algorithm was used to pick electrical periods form the three-phase current signal dataset in Case 1 and Case 2. In Case 1, each current signal was partitioned into about 190 electrical 


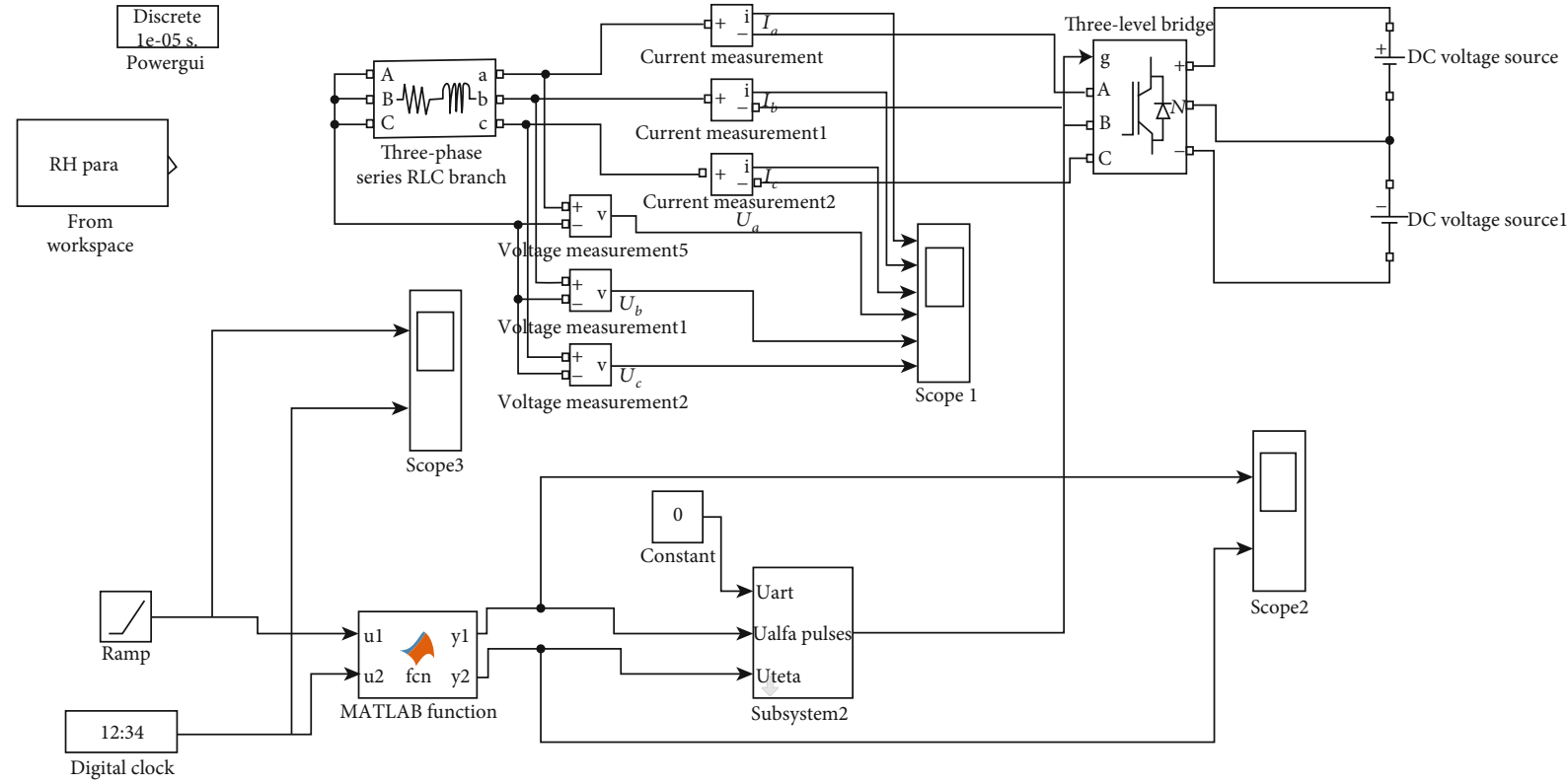

FIGURE 9: Electrical simulation model of three-level inverter.

TABLE 2: Parameter setting of simulation model.

\begin{tabular}{lccccc}
\hline Number & $R(\Omega)$ & $L(\mathrm{mH})$ & Number & $R(\Omega)$ & $L(\mathrm{mH})$ \\
\hline 1 & 1.1 & 1 & 19 & 1.3 & 8 \\
2 & 1.1 & 2 & 20 & 1.3 & 10 \\
3 & 1.1 & 3 & 21 & 1.3 & 20 \\
4 & 1.1 & 5 & 22 & 1.4 & 1 \\
5 & 1.1 & 8 & 23 & 1.4 & 2 \\
6 & 1.1 & 10 & 24 & 1.4 & 3 \\
7 & 1.1 & 20 & 25 & 1.4 & 5 \\
8 & 1.2 & 1 & 26 & 1.4 & 8 \\
9 & 1.2 & 2 & 27 & 1.4 & 10 \\
10 & 1.2 & 3 & 28 & 1.4 & 20 \\
11 & 1.2 & 5 & 29 & 1.5 & 1 \\
12 & 1.2 & 8 & 30 & 1.5 & 2 \\
13 & 1.2 & 10 & 31 & 1.5 & 3 \\
14 & 1.2 & 20 & 32 & 1.5 & 5 \\
15 & 1.3 & 1 & 33 & 1.5 & 8 \\
16 & 1.3 & 2 & 34 & 1.5 & 10 \\
17 & 1.3 & 3 & 35 & 1.5 & 20 \\
18 & 1.3 & 5 & & & \\
\hline
\end{tabular}

periods. As shown in Figure 13(a), current signals at the $S_{\mathrm{a} 1}$ and $S_{\mathrm{a} 2}$ open-circuit fault can be partitioned even in a state of half-cycle malformations or missing output. In the positive half cycle of the $S_{\mathrm{a} 2}$ open current signal in Figure 13(b), all peak positions were rectified by the location of valley positions by AEPP algorithm. In Case 2, each denoised current signal was partitioned into about 246 electrical periods. The partition results of the $S_{\mathrm{a} 1}$ open-circuit signal and $S_{\mathrm{a} 2}$ opencircuit signal are shown in Figures 13(c) and 13(d), respectively. In Figure 13, the peaks and valleys are accurately

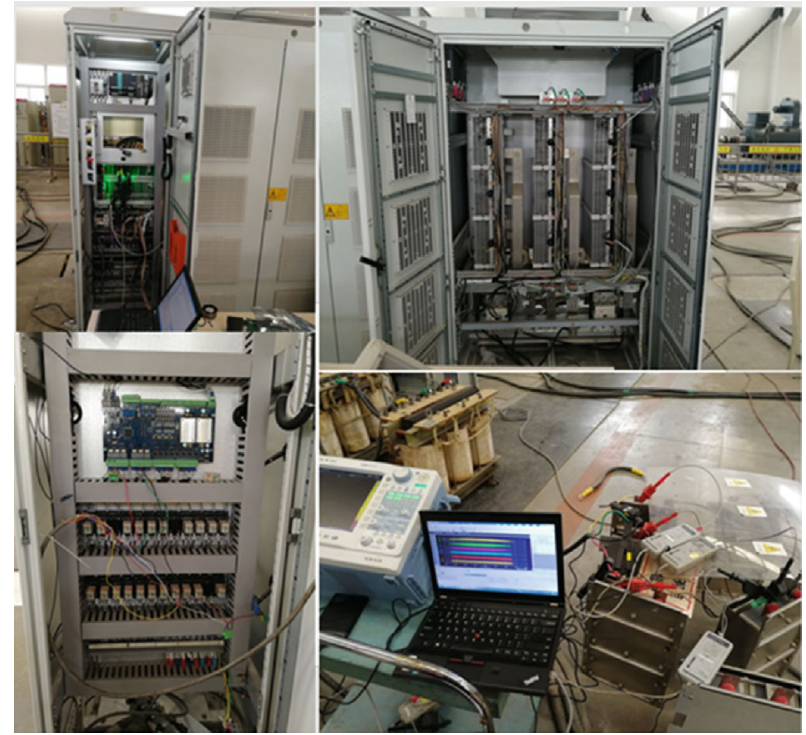

FIGURE 10: Fault current signal acquisition of three-level inverter test-bed.

located in the low frequency stage of the current signal (while the maximum and minimum positions cannot represent peak and valley). After the electrical period partition, we obtained $86450(190 * 455)$ groups of three-phase electrical periods from Case 1 and $63690(246 * 260)$ groups from Case 2.

5.4. Feature Analysis. Features set in Table 1 were computed for each group of three-phase electrical periods after they were normalized by PVM. As an example, for load of $R=1$ $\Omega$ and $H=1 \mathrm{mH}$ in Case 2, the distribution of the range values is shown in Figure 14, which were computed from 


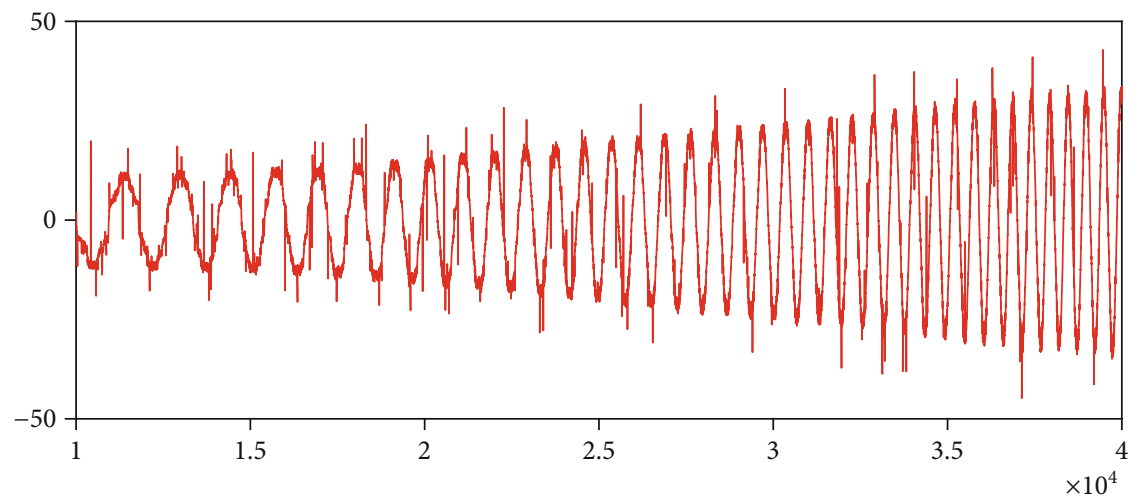

(a) Raw signal

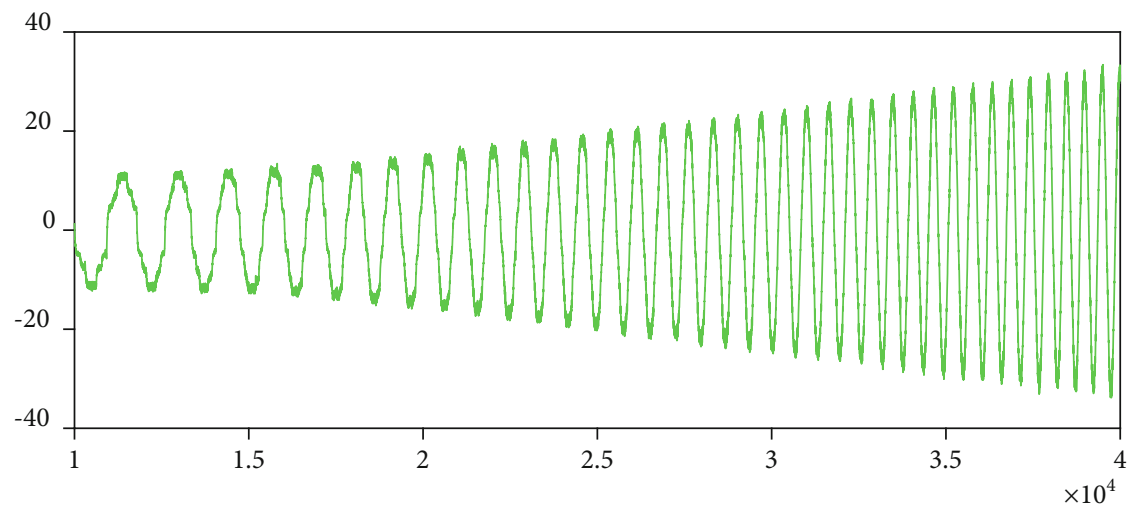

(b) Denoised signal

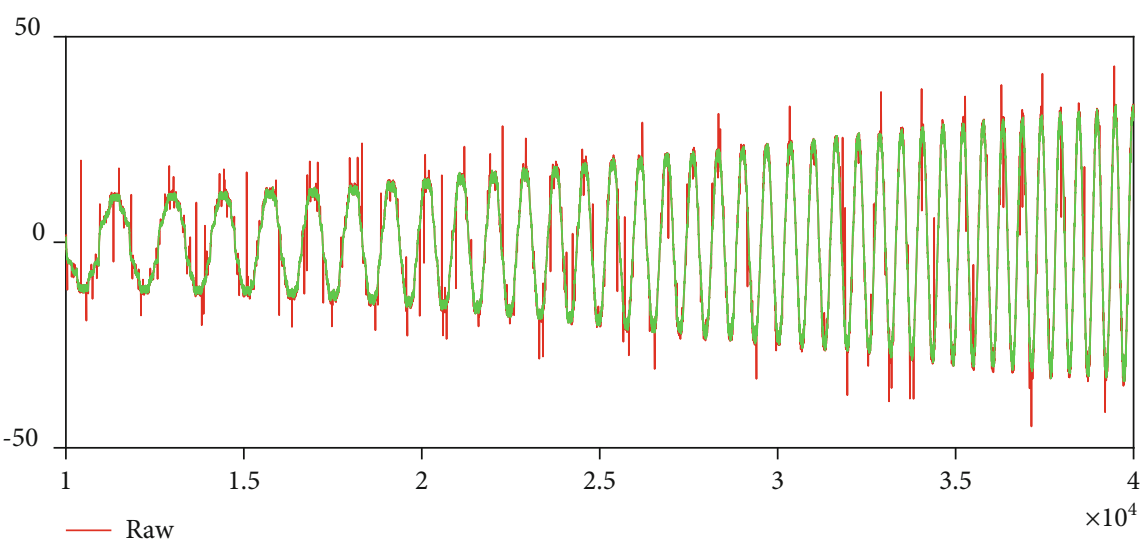

(c) Contrast of two signals

Figure 11: The raw and denoised phase-A current signal of the normal state.

the $3198(246 * 13)$ electrical periods obtained from the phase-A current signals with 13 kinds of inverter states. The horizontal axis represents the serial number of electrical periods, in which the 1-246 represent periods from the normal state, 247-492 represent the Sa1 open-circuit fault, and 2953-3198 represent the Sc4 open-circuit fault, in that order. In Figures 14(a) and 14(b), the range value distributions are computed by normalized and nonnormalized electrical period signals, respectively. Comparing Figures 14(a) and 14(b), we find that the feature computed by the normalized signal has stronger expressive ability. We can also observe that the range feature can help to discriminate open-circuit faults between $S_{\mathrm{a} 1}$ and $S_{\mathrm{a} 2}$, but have no effect on $S_{\mathrm{a} 1}$ and $S_{\mathrm{a} 3}$. The value distributions of some other features are shown in Figure 15, which are also computed from the 3198 (246* 13) periods as mentioned above. The border overlapping of different states for each feature indicates the necessity of preprocessing the original features in order to make them separable and ready for classification. And the disordered structure of original features tends to decrease the performance of the classifier if the feature is directly processed in the classifier. Therefore, in this paper, RF is used for feature 


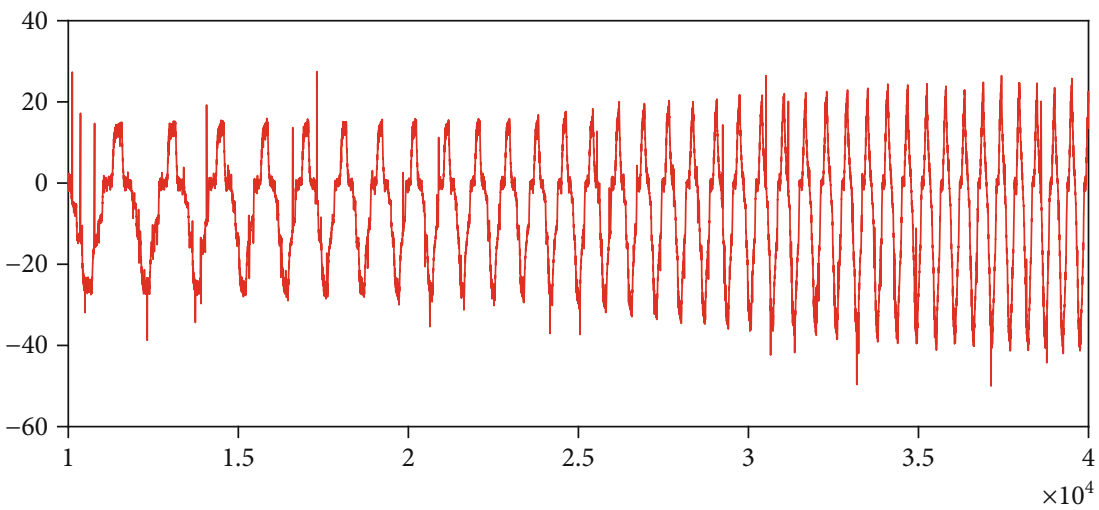

(a) Raw signal

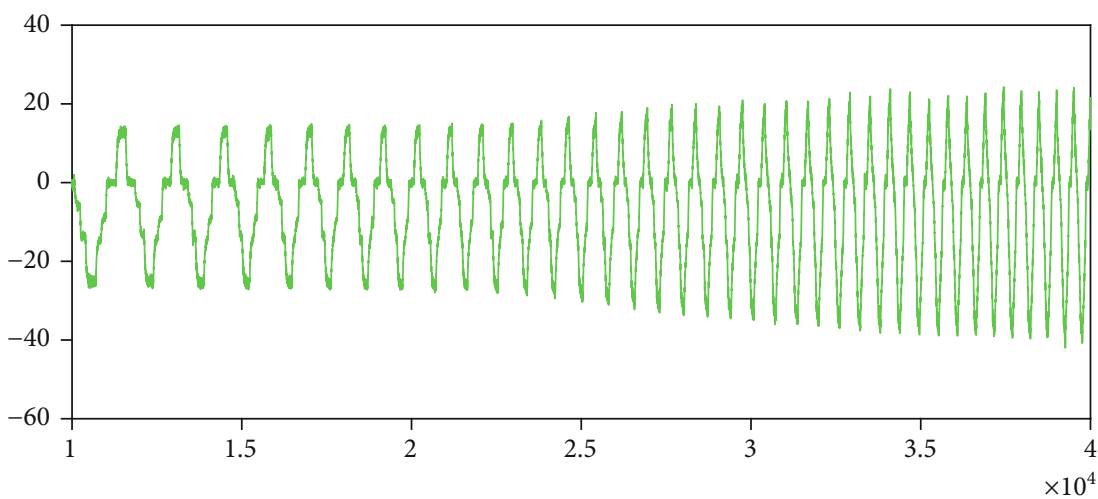

(b) Denoised signal

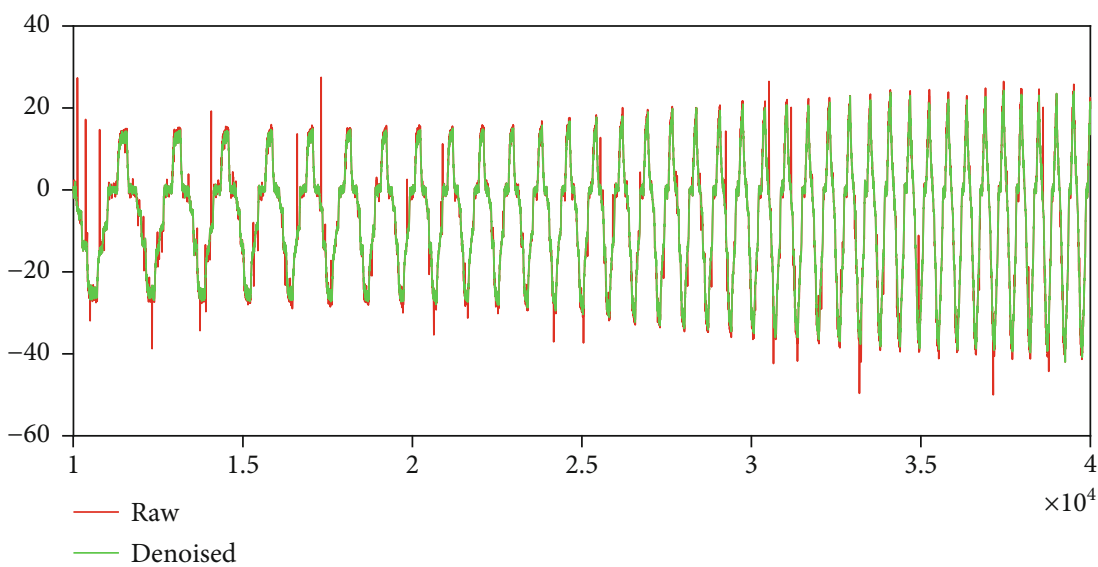

(c) Contrast of two signals

FIgURE 12: The raw and denoised phase-A current signal of Sal open fault.

extraction and open-circuit fault diagnosis because of its feature analysis and classification abilities.

5.5. Results and Discussion. The RF model is used for fault identification with the extracted features from every electrical period-group in three phases (A, B, and C). The 11 features in Table 1 are computed by each electrical period, and features from periods of three phases are grouped as one sample. Therefore, there are $33(11 * 3)$ features data in one sample that are used as the input vector of the RF model. Training and testing datasets of Case 1 and Case 2 are shown in Tables 3 and 4, respectively.
Training time, single sample testing time, and diagnostic accuracy are related to the number of decision trees in the ensemble. The accuracy is affected because of the underfitting if the number of decision trees is too small. As the number of decision trees increases, the test accuracy increases, but the training and test times also increase. The relationship between training time, single sample testing time, and the number of decision trees in the random forest is shown in Figure 16. With the increase of the number of decision trees, the training time also increases. As shown in Figure 17(a), the relationship between diagnostic accuracy and the number of decision trees is a parabolic type of curve. When the number 

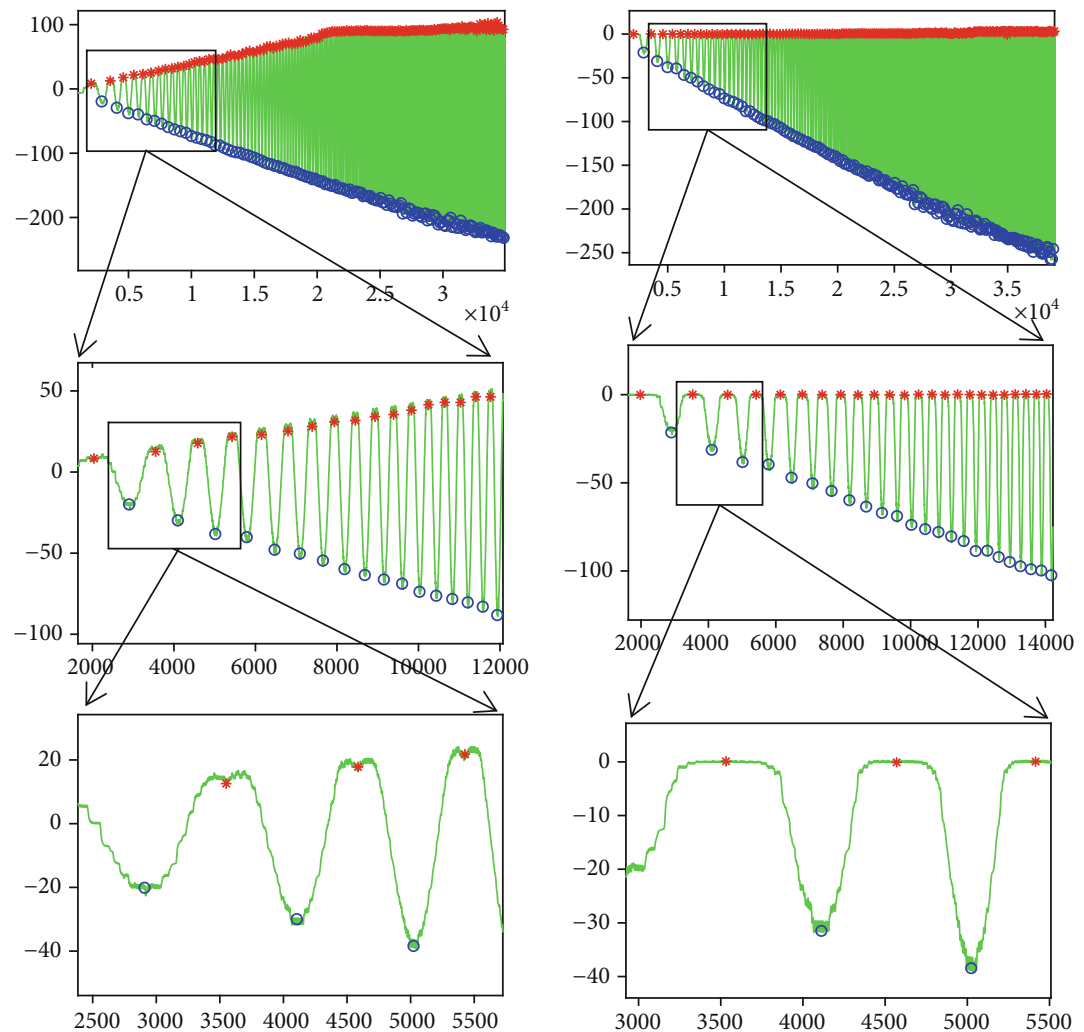

(a) Case 1: $S_{\text {a1 }}$ open circuit failure

(b) Case 1: $S_{\mathrm{a} 2}$ open circuit failure
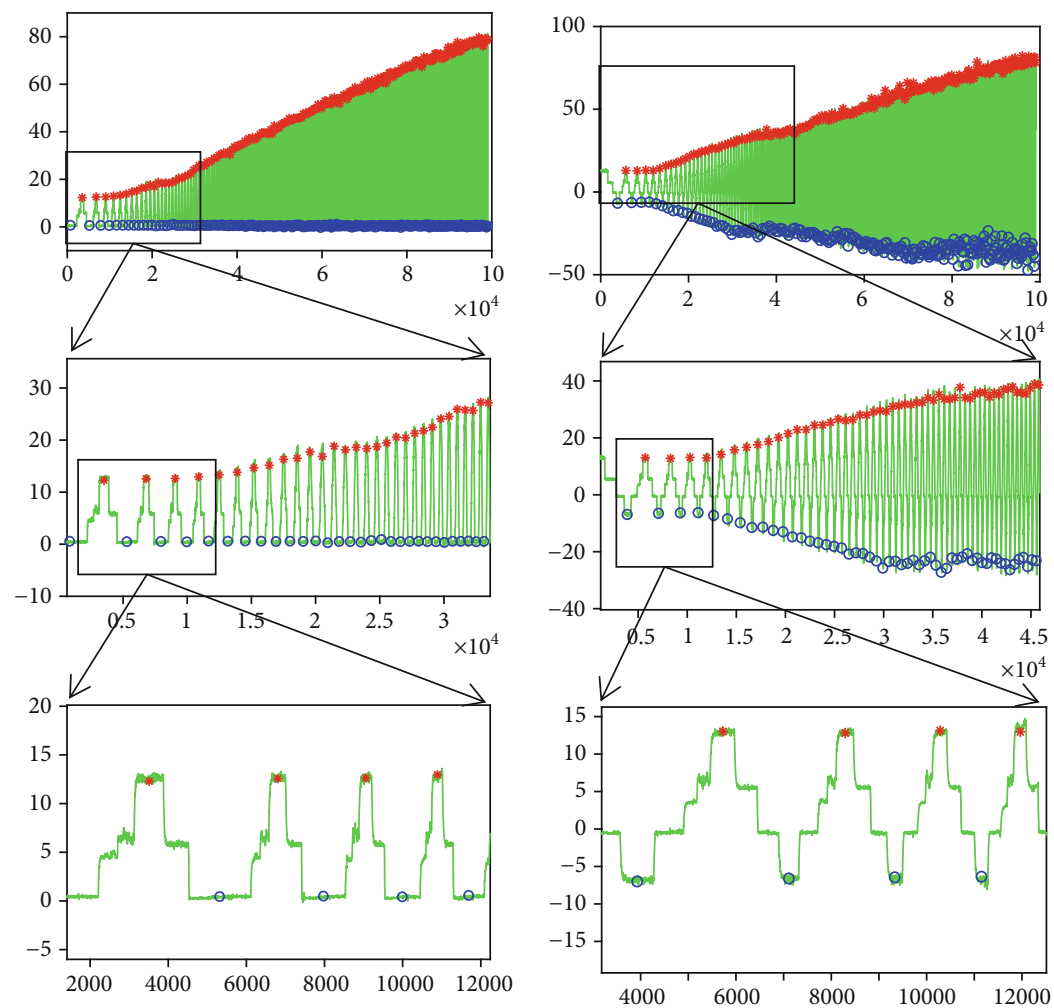

(c) Case 2: $S_{\mathrm{a} 3}$ open circuit failure

(d) Case 2: $S_{\mathrm{a} 4}$ open circuit failure

FIGURE 13: Single-phase division result of phase-A current signal. 


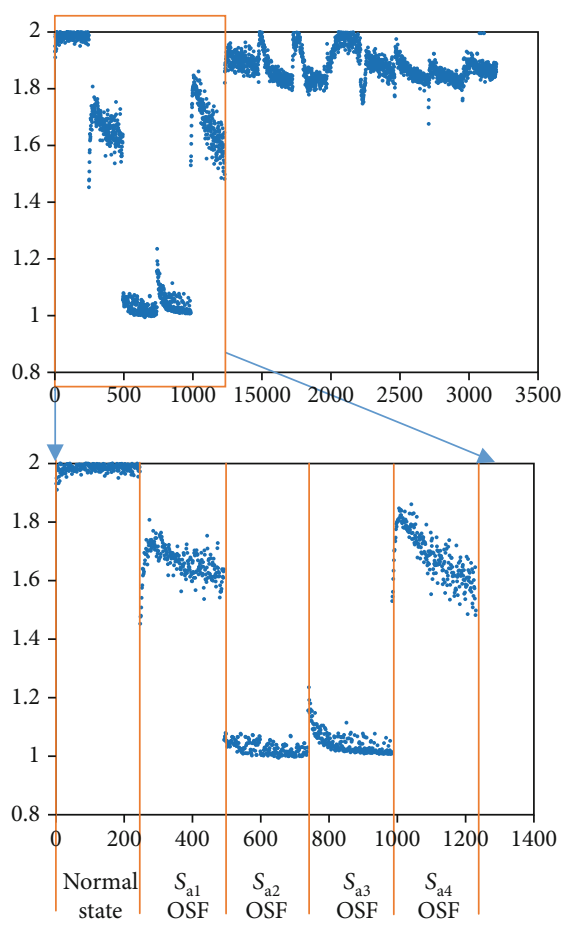

(a) Range value distribution of normalized electrical period of phase-A current

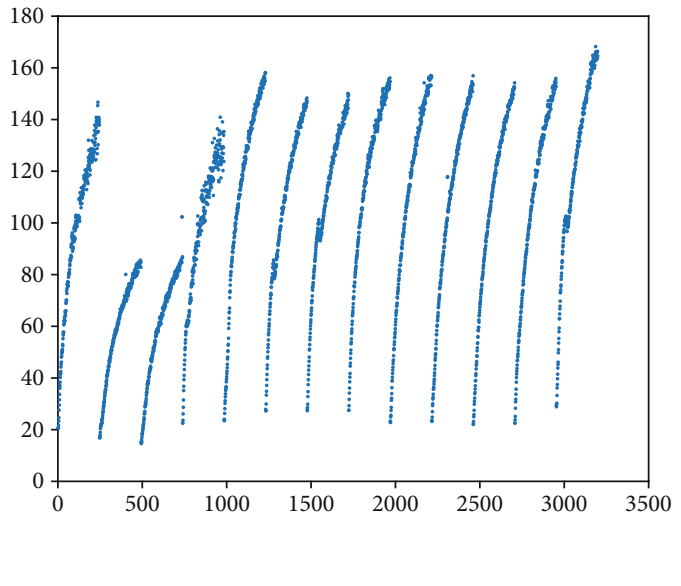

(b) Range value distribution of nonnormalized electrical period of phase-A current

FIGURE 14: Range value distribution of normalized and nonnormalized electrical period of phase-A current.

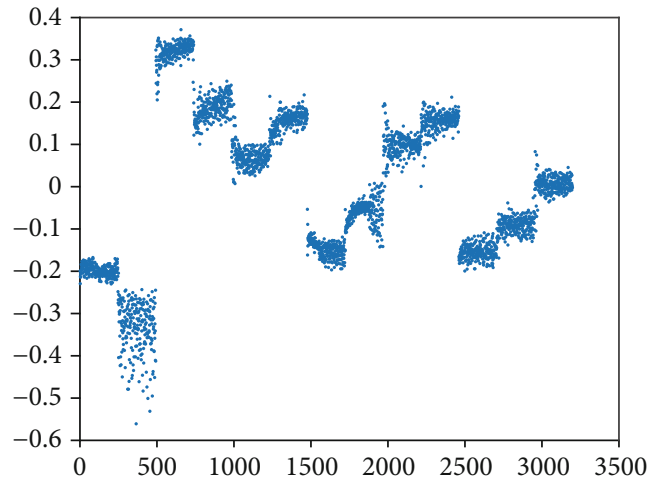

(a) Mean value

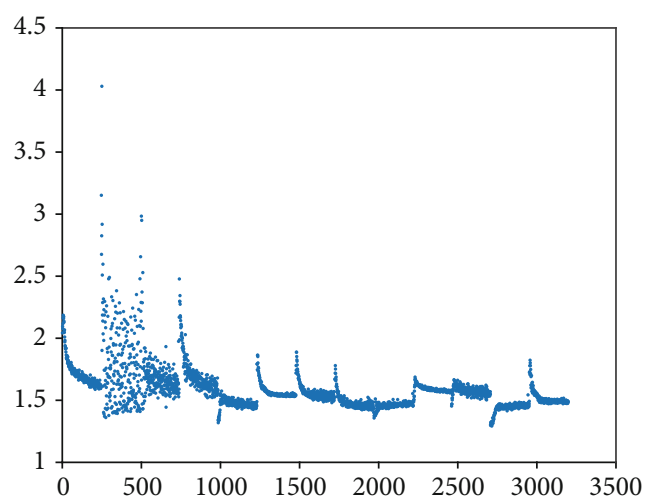

(c) Skewness

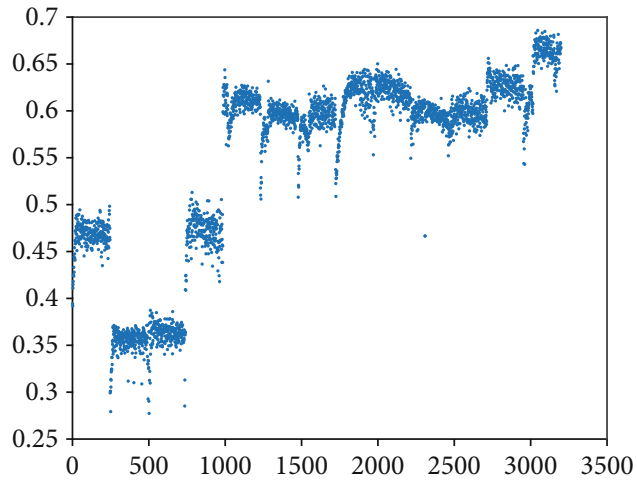

(b) Standard deviation

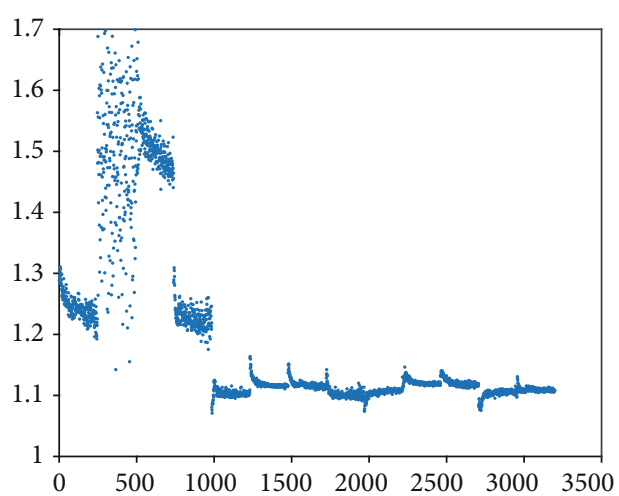

(d) Shape factor

Figure 15: Value distribution of features computed form normalized electrical periods of phase-A current. 
TABLE 3: Training and testing dataset in Case 1.

\begin{tabular}{lcc}
\hline & Training set & Testing set \\
& $R=1.1 \Omega$ and $R=1.5 \Omega$ & $R=1.2 \Omega, R=1.3 \Omega, R=1.4 \Omega$ \\
& All 7 types of capacitors & All 7 types of capacitors \\
\hline Numbers of sample & $190 \times 2 \times 7 \times 13$ & $190 \times 3 \times 7 \times 13$ \\
Explanation & $190 \times 2 \times 7 \times 13: 190$ electrical periods from each signal, 2 types of resistances, 7 types of \\
& & capacitors, 13 types of states \\
\hline
\end{tabular}

TABle 4: Training and testing dataset in Case 1.

\begin{tabular}{lcc}
\hline & $\begin{array}{c}\text { Training set } \\
R=0.5 \Omega, L=1.5 \mathrm{mH}\end{array}$ & $\begin{array}{c}\text { Testing set } \\
\text { Numbers of sample } \\
\text { Explanation }\end{array}$ \\
\hline
\end{tabular}

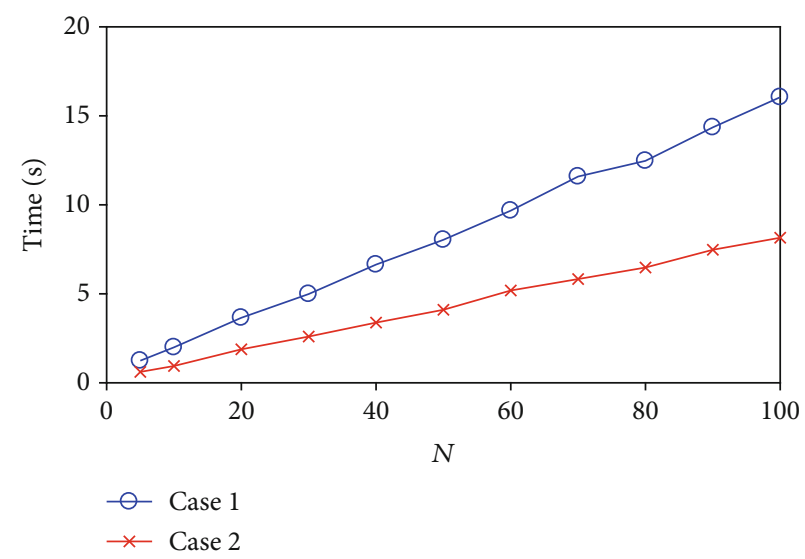

(a) Training time

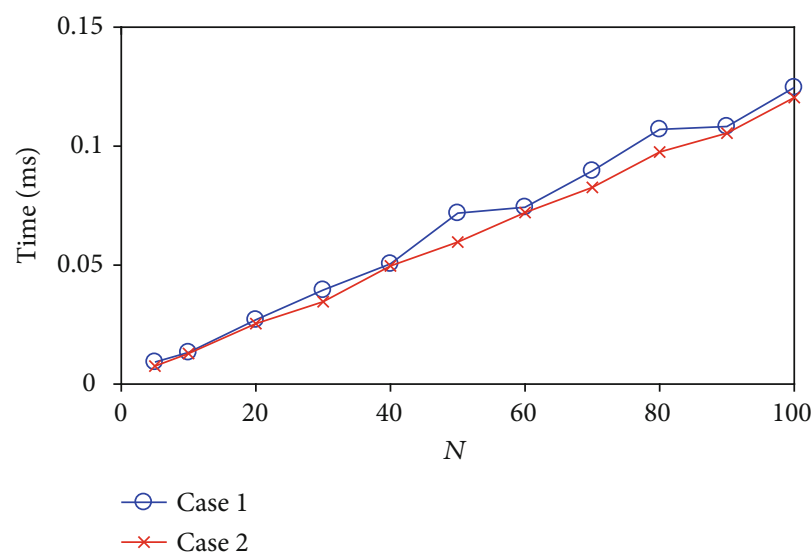

(b) Testing time for one sample

FIgURE 16: Training and testing times for different numbers of decision trees.

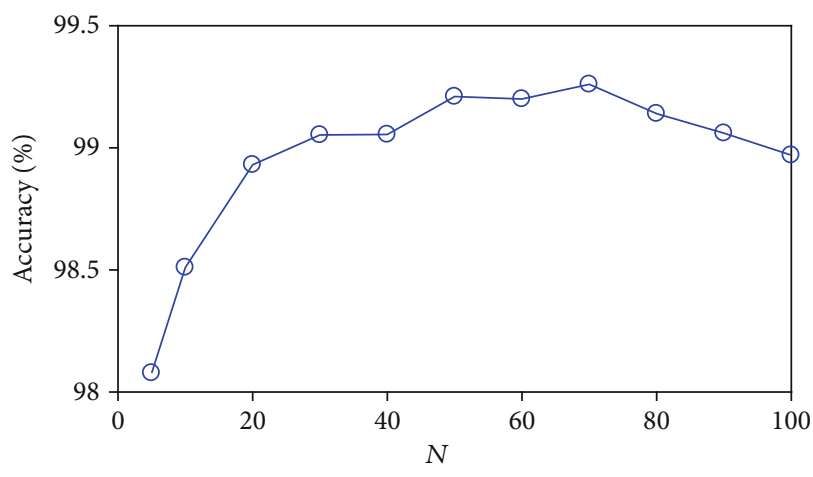

(a) Case 1: testing accuracy

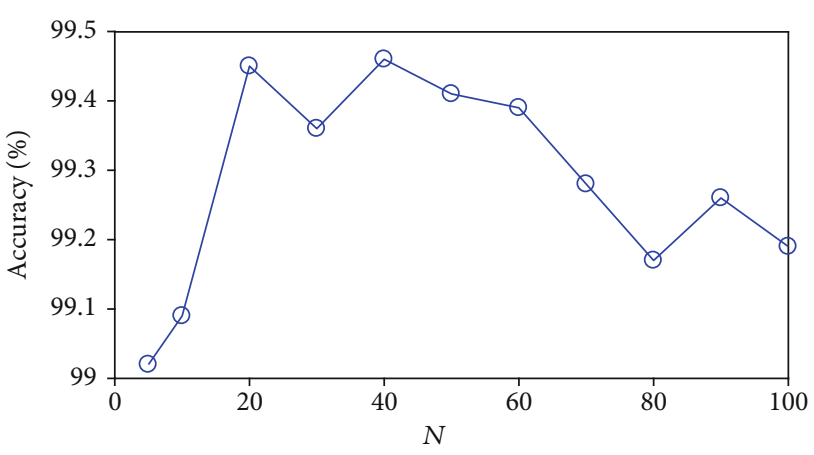

(b) Case 2: testing accuracy

Figure 17: Diagnostic accuracy for different numbers of decision trees.

of decision trees increases from 70 to 100 , the diagnostic accuracy decreases slightly. As shown in Figure 17(b), the diagnostic accuracy keeps a high level between 20 and 60 . When the number of decision trees is greater than 50 , accuracy does not rise, which causes overfitting problems. In summary, the optimal number of decision trees is 50 in this paper.
Figure 18 presents the confusion matrix of the result of the detection when the tree number is 50 . The rows stand for the actual label, and the columns stand for the predicted label for each condition. The diagonal elements in the matrix represent the number of correctly classified samples of each class, and off-diagonal elements represent misclassified 


\begin{tabular}{|c|ccccccccccccc|}
$S_{\mathrm{a} 1}$ & 99.0 & 0.5 & 0.0 & 0.3 & 0.2 & 0.0 & 0.0 & 0.0 & 0.0 & 0.0 & 0.0 & 0.0 & 0.0 \\
$S_{\mathrm{a} 2}$ & 0.1 & 99.8 & 0.0 & 0.0 & 0.0 & 0.0 & 0.0 & 0.0 & 0.0 & 0.0 & 0.0 & 0.0 & 0.0 \\
$S_{\mathrm{a} 3}$ & 0.0 & 0.0 & 99.7 & 0.3 & 0.0 & 0.0 & 0.0 & 0.0 & 0.0 & 0.0 & 0.0 & 0.0 & 0.0 \\
$S_{\mathrm{a} 4}$ & 0.0 & 0.0 & 0.5 & 99.5 & 0.0 & 0.0 & 0.0 & 0.0 & 0.0 & 0.0 & 0.0 & 0.0 & 0.0 \\
$S_{\mathrm{b} 1}$ & 0.0 & 0.0 & 0.0 & 0.0 & 98.2 & 1.3 & 0.0 & 0.2 & 0.3 & 0.0 & 0.0 & 0.0 & 0.0 \\
$S_{\mathrm{b} 2}$ & 0.0 & 0.0 & 0.0 & 0.0 & 0.9 & 99.1 & 0.0 & 0.0 & 0.0 & 0.0 & 0.0 & 0.0 & 0.0 \\
$S_{\mathrm{b} 3}$ & 0.0 & 0.0 & 0.0 & 0.0 & 0.0 & 0.0 & 100.0 & 0.0 & 0.0 & 0.0 & 0.0 & 0.0 & 0.0 \\
$S_{\mathrm{b} 4}$ & 0.0 & 0.0 & 0.0 & 0.0 & 0.3 & 0.0 & 0.6 & 98.9 & 0.0 & 0.0 & 0.0 & 0.2 & 0.0 \\
$S_{\mathrm{c} 1}$ & 0.2 & 0.0 & 0.0 & 0.0 & 0.2 & 0.0 & 0.0 & 0.0 & 98.3 & 1.1 & 0.0 & 0.2 & 0.0 \\
$S_{\mathrm{c} 2}$ & 0.0 & 0.0 & 0.0 & 0.0 & 0.0 & 0.0 & 0.0 & 0.0 & 1.0 & 99.0 & 0.0 & 0.0 & 0.0 \\
$S_{\mathrm{c} 3}$ & 0.0 & 0.0 & 0.0 & 0.0 & 0.0 & 0.0 & 0.0 & 0.0 & 0.0 & 0.0 & 99.5 & 0.5 & 0.0 \\
$S_{\mathrm{c} 4}$ & 0.0 & 0.0 & 0.0 & 0.1 & 0.0 & 0.0 & 0.0 & 0.1 & 0.3 & 0.0 & 0.8 & 98.6 & 0.0 \\
Normal & 0.0 & 0.0 & 0.0 & 0.0 & 0.0 & 0.0 & 0.0 & 0.0 & 0.0 & 0.0 & 0.0 & 0.0 & 100.0 \\
\hline
\end{tabular}

(a) Case 1

\begin{tabular}{|c|c|c|c|c|c|c|c|c|c|c|c|c|c|}
\hline$S_{\mathrm{a} 1}$ & 99.0 & 0.0 & 0.0 & 0.7 & 0.2 & 0.0 & 0.0 & 0.0 & 0.0 & 0.0 & 0.0 & 0.0 & 0.0 \\
\hline$S_{\mathrm{a} 2}$ & 0.0 & 100.0 & 0.0 & 0.0 & 0.0 & 0.0 & 0.0 & 0.0 & 0.0 & 0.0 & 0.0 & 0.0 & 0.0 \\
\hline$S_{\mathrm{a} 3}$ & 0.0 & 0.0 & 100.0 & 0.0 & 0.0 & 0.0 & 0.0 & 0.0 & 0.0 & 0.0 & 0.0 & 0.0 & 0.0 \\
\hline$S_{\mathrm{a} 4}$ & 0.6 & 0.0 & 0.0 & 99.3 & 0.0 & 0.0 & 0.0 & 0.2 & 0.0 & 0.0 & 0.0 & 0.0 & 0.0 \\
\hline$S_{b_{1}}$ & 0.0 & 0.0 & 0.0 & 0.0 & 99.1 & 0.0 & 0.0 & 0.9 & 0.0 & 0.0 & 0.0 & 0.0 & 0.0 \\
\hline$S_{\mathrm{b} 2}$ & 0.0 & 0.0 & 0.0 & 0.0 & 0.0 & 100.0 & 0.0 & 0.0 & 0.0 & 0.0 & 0.0 & 0.0 & 0.0 \\
\hline$S_{\mathrm{b} 3}$ & 0.0 & 0.0 & 0.0 & 0.0 & 0.0 & 0.0 & 100.0 & 0.0 & 0.0 & 0.0 & 0.0 & 0.0 & 0.0 \\
\hline$S_{\mathrm{b} 4}$ & 0.0 & 0.0 & 0.0 & 0.2 & 2.9 & 0.0 & 0.0 & 96.8 & 0.0 & 0.0 & 0.0 & 0.2 & 0.0 \\
\hline$S_{\mathrm{cl}}$ & 0.1 & 0.0 & 0.0 & 0.0 & 0.2 & 0.0 & 0.0 & 0.0 & 99.3 & 0.0 & 0.0 & 0.5 & 0.0 \\
\hline$S_{c 2}$ & 0.0 & 0.0 & 0.0 & 0.0 & 0.0 & 0.0 & 0.0 & 0.0 & 0.0 & 100.0 & 0.0 & 0.0 & 0.0 \\
\hline$S_{c^{3}}$ & 0.0 & 0.0 & 0.0 & 0.0 & 0.0 & 0.0 & 0.0 & 0.0 & 0.0 & 0.0 & 100.0 & 0.0 & 0.0 \\
\hline$S_{c 4}$ & 0.0 & 0.0 & 0.0 & 0.0 & 0.0 & 0.0 & 0.0 & 0.2 & 0.9 & 0.0 & 0.0 & 98.9 & 0.0 \\
\hline ormal & 0.2 & 0.0 & 0.0 & 0.0 & 0.1 & 0.0 & 0.0 & 0.2 & 0.0 & 0.0 & 0.0 & 0.0 & 99.6 \\
\hline & $S_{\mathrm{a} 1}$ & $S_{\mathrm{a} 2}$ & $S_{\mathrm{a3}}$ & $S_{\mathrm{a} 4}$ & $S_{b_{1}}$ & $S_{\mathrm{b} 2}$ & $S_{\mathrm{b} 3}$ & $S_{\mathrm{b} 4}$ & $S_{c 1}$ & $S_{c 2}$ & $S_{c 3}$ & $S_{c 4}$ & Norma \\
\hline
\end{tabular}

(b) Case 2

FIGURE 18: Confusion matrix of the result on datasets of Case 1 and Case 2.

samples. The confusion matrix of the result of Case 1 is shown in Figure 18(a). It shows that $S_{\mathrm{b} 3}$ and normal have $100 \%$ accuracy. $S_{\mathrm{cl}}$ is the worst one with the accuracy of $98.3 \% . S_{\mathrm{c} 2}$ receives the most misclassification that $1.1 \%$ out of $S_{\mathrm{c} 1}$ are misclassified to $S_{\mathrm{c} 2}$. Normal has $100 \%$ accuracy, and no other condition is misclassified to it; it means the proposed fault diagnosis method can accurately determine whether a fault has occurred in Case 1. The overall accuracy of Case 1 is $99.21 \%$. Figure 18(b) shows the confusion matrix of the result of Case 2. $S_{\mathrm{a} 2}, S_{\mathrm{a} 3}, S_{\mathrm{b} 2}, S_{\mathrm{b} 3}, S_{\mathrm{c} 2}$, and $S_{\mathrm{c} 3}$ have $100 \%$ accuracy. $S_{\mathrm{b} 4}$ is the worst one with the accuracy of $96.8 \% . S_{\mathrm{b} 1}$ receives the most misclassification that $0.2 \%$ out of $S_{\mathrm{a} 1}, 2.9 \%$ out of $S_{\mathrm{b} 4}, 0.2 \%$ out of $S_{\mathrm{cl}}$, and $0.1 \%$ out of normal are misclassified to $S_{\mathrm{b} 1}$. The overall accuracy of Case 2 is $99.38 \%$.

5.6. Comparison of Diagnosis Methods. Comparative experiments of six groups were carried out, including PCA-SVM, LDA-SVM, PCA-KNN, and LDA-KNN. In the PCA, the cumulative principal component contribution rate was $95 \%$. In the LDA, the dimension of LDA dimension reduction was 5 . In the $\mathrm{KNN}$, the nearest number was 5 , the distance was "cosine," and the rule was the nearest. The accuracies of the different diagnosis methods are shown in Table 5. By comparing different methods, we find that the combination
TABle 5: Accuracy of fault identification for different models.

\begin{tabular}{lcc}
\hline Diagnosis method & Case 1 accuracy rate & Case 2 accuracy rate \\
\hline SVM & $95.38 \%$ & $95.91 \%$ \\
PCA + SVM & $93.07 \%$ & $95.65 \%$ \\
LDA + SVM & $96.59 \%$ & $97.28 \%$ \\
KNN & $85.52 \%$ & $87.98 \%$ \\
PCA + KNN & $86.68 \%$ & $87.56 \%$ \\
LDA + KNN & $89.36 \%$ & $91.28 \%$ \\
RF-proposed & $99.21 \%$ & $99.38 \%$ \\
\hline
\end{tabular}

of AEPP, PVM, MODWT, and RF has the highest accuracy in fault diagnosis of the NPC three-level inverter.

\section{Conclusions}

In this paper, identifying the open-circuit fault in an IGBT in the NPC three-level inverter was analyzed and studied. A novel fault diagnosis system is implemented using PVM, MODWT, and RF. Three-phase current signals in different fault types and during an acceleration process at variable load conditions are sampled as the raw signals for the system. And 
an adaptive period partition method is designed to accurately pick the electrical periods from the real-time current signals. The electrical period is decomposed by three-level MODWT, and only low-frequency approximation component is retained for feature extraction. 33 features computed from lowfrequency component which is normalized by PVM are used as the input vector to train the RF model. Simulation and test-bed experiments show that the method designed in this paper has good diagnostic capability, and the diagnostic accuracy rates are $99.21 \%$ and $99.38 \%$, respectively.

This paper combines AEPP, PVM, MODWT, and RF, which are used for signal analysis, feature extraction, and fault identification. The experimental results show that compared with other classification methods, based on the RF model, the fault diagnosis model can effectively improve the accuracy of fault identification and exhibits strong adaptability, which can be used in the actual inverter fault diagnosis system, especially for a shifting process. Improving the diagnostic accuracy and discovering more fault patterns and features are the main future research work.

\section{Data Availability}

The data used to support the findings of this study are available from the corresponding author upon request.

\section{Conflicts of Interest}

We declare that we do not have any commercial or associative interest that represents a conflict of interest in connection with the work submitted.

\section{Acknowledgments}

This work was supported by Special Funds Project for Transforming Scientific and Technological Achievements in Jiangsu Province (BA2016017) and the National Key R\&D Program of China (2017YFC0804400 and 2017YFC0804401).

\section{References}

[1] V. Smet, F. Forest, J. J. Huselstein et al., "Ageing and failure modes of IGBT modules in high-temperature power cycling," IEEE Transactions on Industrial Electronics, vol. 58, no. 10, pp. 4931-4941, 2011.

[2] Y. Yu and S. Pei, "Open-circuit fault diagnosis of neutral point clamped three-level inverter based on sparse representation," IEEE Access, vol. 6, pp. 73499-73508, 2018.

[3] K. Zhang, C. Peng, and Z. Kang, "Health diagnosis method of power distribution equipment based on holographic timescalar measurement data," Computer Measurement \& Control, vol. 26, no. 3, pp. 29-34, 2018.

[4] S. M. Kim, J. S. Lee, and K. B. Lee, "A modified level-shifted PWM strategy for fault-tolerant cascaded multilevel inverters with improved power distribution," IEEE Transactions on Industrial Electronics, vol. 63, no. 11, pp. 7264-7274, 2016.

[5] H. Yan, Y. Xu, J. Zou, Y. Fang, and F. Cai, "A novel opencircuit fault diagnosis method for voltage source inverters with a single current sensor," IEEE Transactions on Power Electronics, vol. 33, no. 10, pp. 8775-8786, 2018.
[6] Z. Wang, Z. Huang, C. Song, and H. Zhang, "Multiscale adaptive fault diagnosis based on signal symmetry reconstitution preprocessing for microgrid inverter under changing load condition," IEEE Transactions on Smart Grid, vol. 9, no. 2, pp. 797-806, 2018.

[7] M. Trabelsi, M. Boussak, and M. Benbouzid, "Multiple criteria for high performance real-time diagnostic of single and multiple open-switch faults in ac-motor drives: application to IGBT-based voltage source inverter," Electric Power Systems Research, vol. 144, pp. 136-149, 2017.

[8] C. Shu, C. Ya-Ting, Y. Tian-Jian, and W. Xun, "A novel diagnostic technique for open-circuited faults of inverters based on output line-to-line voltage model," IEEE Transactions on Industrial Electronics, vol. 63, no. 7, pp. 4412-4421, 2016.

[9] L. M. A. Caseiro and A. M. S. Mendes, "Real-time IGBT opencircuit fault diagnosis in three-level neutral-point-clamped voltage-source rectifiers based on instant voltage error," IEEE Transactions on Industrial Electronics, vol. 62, no. 3, pp. 1669-1678, 2015.

[10] X. Wu, R. Tian, S. Cheng, T. Chen, and L. Tong, "A nonintrusive diagnostic method for open-circuit faults of locomotive inverters based on output current trajectory," IEEE Transactions on Power Electronics, vol. 33, no. 5, pp. 4328-4341, 2018.

[11] C. Yong, L. Zhilong, and C. Zhangyong, "Fast diagnosis and location method for open-circuit fault in inverter based on current vector character analysis," Transactions of China Electrotechnical Society, vol. 33, no. 4, pp. 883-891, 2018.

[12] A. M. Santos Mendes, S. M. A. Cruz, and M. B. Abadi, "Fault diagnostic algorithm for three-level neutral point clamped AC motor drives, based on the average current Park's vector," IET Power Electronics, vol. 7, no. 5, pp. 1127-1137, 2014.

[13] M. Sital-Dahone, A. Saha, Y. Sozer, and A. Mpanda, "Multiple device open circuit fault diagnosis for neutral-point-clamped inverters," in 2017 IEEE Applied Power Electronics Conference and Exposition (APEC), Tampa, FL, USA, 2017.

[14] X. Ge, J. Pu, B. Gou, and Y.-C. Liu, “An open-circuit fault diagnosis approach for single-phase three-level neutral-pointclamped converters," IEEE Transactions on Power Electronics, vol. 33, no. 3, pp. 2559-2570, 2018.

[15] A. Joseph, T. R. Chelliah, R. Selvaraj, and K. B. Lee, "Fault diagnosis and fault-tolerant control of megawatt power electronic converter-fed large-rated asynchronous hydrogenerator," IEEE Journal of Emerging and Selected Topics in Power Electronics, vol. 7, no. 4, pp. 2403-2416, 2019.

[16] J. He, N. A. O. Demerdash, N. Weise, and R. Katebi, “A fast on-line diagnostic method for open-circuit switch faults in SiC-MOSFET based T-type multilevel inverters," IEEE Transactions on Industry Applications, vol. 53, no. 3, pp. 2948-2958, 2017.

[17] I. Jlassi, J. O. Estima, S. K. el Khil, N. M. Bellaaj, and A. J. M. Cardoso, "A robust observer-based method for IGBTs and current sensors fault diagnosis in voltage-source inverters of PMSM drives," IEEE Transactions on Industry Applications, vol. 53, no. 3, pp. 2894-2905, 2017.

[18] T. Yang, H. Pen, Z. Wang, and C. S. Chang, "Feature knowledge based fault detection of induction motors through the analysis of stator current data," IEEE Transactions on Instrumentation and Measurement, vol. 65, no. 3, pp. 549-558, 2016.

[19] B. Cai, Y. Zhao, H. Liu, and M. Xie, "A data-driven fault diagnosis methodology in three-phase inverters for PMSM drive systems," IEEE Transactions on Power Electronics, vol. 32, no. 7, pp. 5590-5600, 2017. 
[20] S. Lin, Z. Liu, and K. Hu, "Traction inverter open switch fault diagnosis based on Choi-Williams distribution spectral kurtosis and wavelet-packet energy Shannon entropy," Entropy, vol. 19, no. 9, pp. 504-523, 2017.

[21] Z. Huang, Z. Wang, and H. Zhang, "A diagnosis algorithm for multiple open-circuited faults of microgrid inverters based on main fault component analysis," IEEE Transactions on Energy Conversion, vol. 33, no. 3, pp. 925-937, 2018.

[22] R. B. Dhumale and S. D. Lokhande, "Neural network fault diagnosis of voltage source inverter under variable load conditions at different frequencies," Measurement, vol. 91, pp. 565$575,2016$.

[23] M. Fei, L. Ning, M. Huiyu, P. Yi, S. Haoyuan, and Z. Jianyong, "On-line fault diagnosis model for locomotive traction inverter based on wavelet transform and support vector machine," Microelectronics Reliability, vol. 88-90, pp. 12741280, 2018.

[24] T. Wang, J. Qi, H. Xu, Y. Wang, L. Liu, and D. Gao, "Fault diagnosis method based on FFT-RPCA-SVM for cascadedmultilevel inverter," ISA Transactions, vol. 60, pp. 156-163, 2016.

[25] R. B. Dhumale and S. D. Lokhande, "Diagnosis of multiple open switch faults in three phase voltage source inverter," Journal of Intelligent Fuzzy Systems, vol. 30, no. 4, pp. 20552065, 2016.

[26] A. M. S. Mendes, A. J. M. Cardoso, and E. S. Saraiva, "Voltage source inverter fault diagnosis in variable speed AC drives, by the average current Park's vector approach," in IEEE International Electric Machines and Drives Conference. IEMDC'99. Proceedings (Cat. No.99EX272), pp. 704-706, Seattle, WA, USA, 1999.

[27] J. H. Park, D. H. Kim, S. S. Kim, D. J. Lee, and M. G. Chun, "C-ANFIS based fault diagnosis for voltage-fed PWM motor drive systems," in IEEE Annual Meeting of the Fuzzy Information, 2004. Processing NAFIPS '04., pp. 379-383, Banff, Alberta, Canada, 2004.

[28] D. K. Alves, F. B. Costa, R. Lucio de Araujo Ribeiro, C. Martins de Sousa Neto, and T. de Oliveira Alves Rocha, "Real-time power measurement using the maximal overlap discrete wavelet-packet transform," IEEE Transactions on Industrial Electronics, vol. 64, no. 4, pp. 3177-3187, 2017.

[29] L. Breiman, "Random forests," Machine Learning, vol. 45, no. 1, pp. 5-32, 2001. 


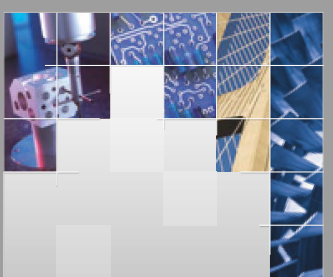

\section{Enfincering}
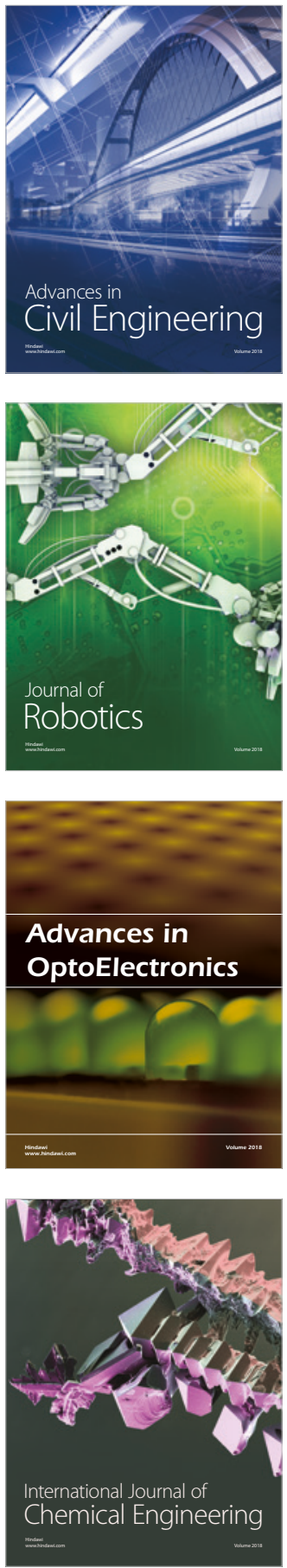

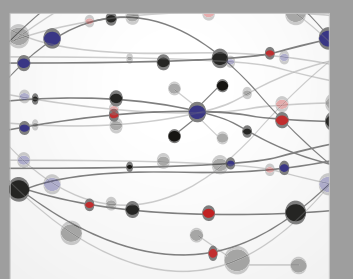

\section{Rotating \\ Machinery}

The Scientific World Journal

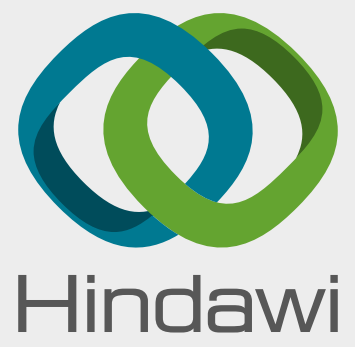

Submit your manuscripts at

www.hindawi.com
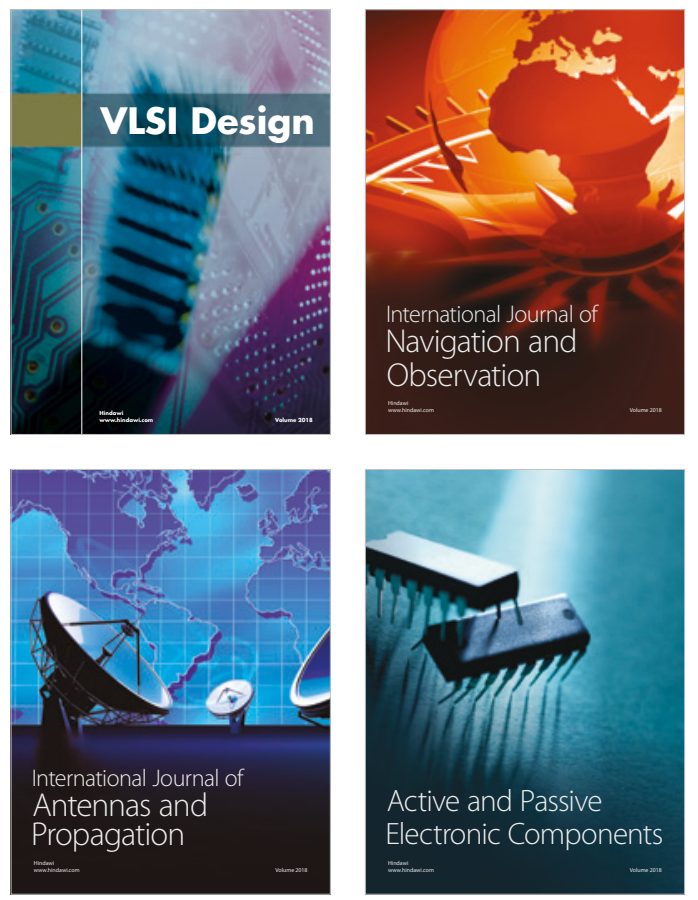
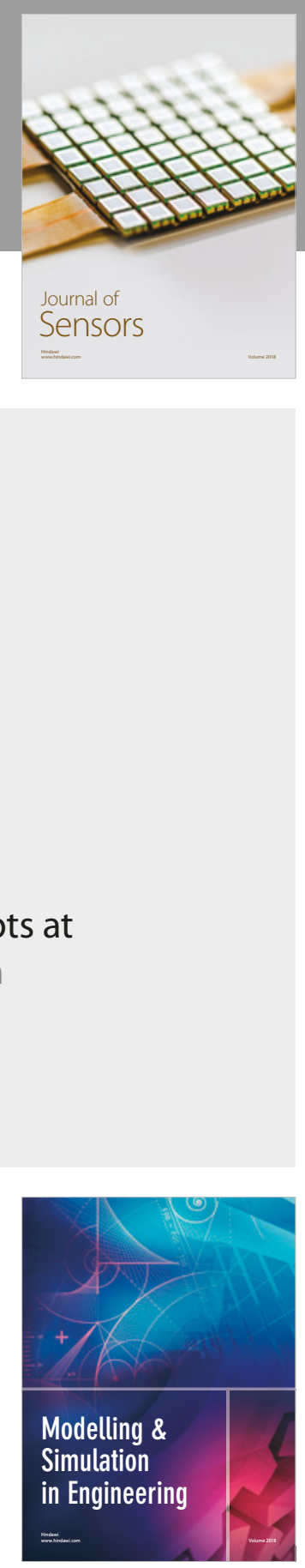

\section{Advances \\ Multimedia}
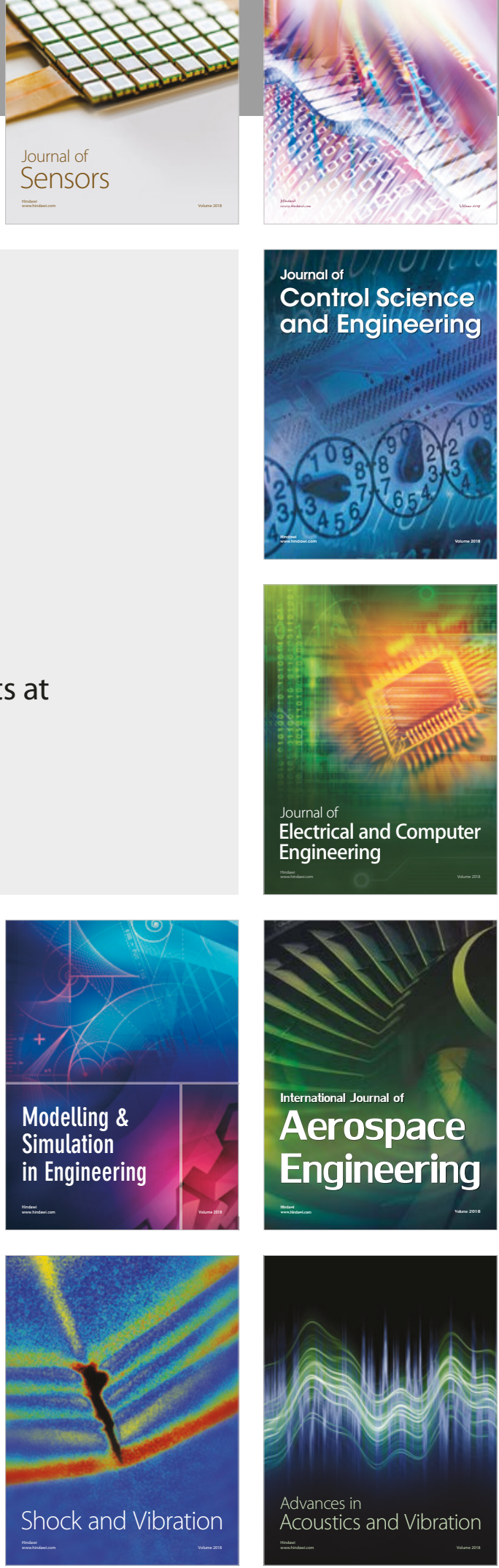